Revista Universo Contábil, ISSN 1809-3337

Blumenau, v. 14, n. 1, p. 115-142, jan./mar., 2018

doi:10.4270/ruc.2018106

Disponível em www.furb.br/universocontabil

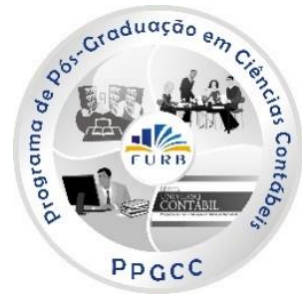

\title{
DETERMINANTES DA AVERSÃO À PERDA EM DECISÕES FINANCEIRAS: UMA INVESTIGAÇÃO POR MEIO DE MODELOS FATORIAIS ${ }^{1}$
}

\section{DETERMINANTS TO LOSS AVERSION FROM FINANCIAL DECISIONS: AN INVESTIGATION BY MEANS OF FACTORIAL MODELS}

\section{DETERMINANTES DE LA AVERSIÓN A LA PÉRDIDA EN DECISIONES FINANCIERAS: UNA INVESTIGACIÓN A TRAVÉS DE MODELOS DE MODELOS FACTORIALES}

Clayton Levy Lima de Melo

Doutor em Ciências Contábeis pela Universidade de Brasília Professor do Departamento de Ciências Contábeis da Universidade Federal do Rio Grande do Norte Endereço: Campus Universitário - UFRN, Lagoa Nova - Caixa Postal: 1524 CEP: $59000-000$ - Natal - RN - Brasil

E-mail: clayton_levy@hotmail.com Telefone: (84) 3215-3486

Anderson Luiz Rezende Mól

Doutor em Administração pela Universidade Federal de Lavras Professor do Departamento de Administração da Universidade Federal do Rio Grande do Norte Endereço: Campus Universitário - UFRN, Lagoa Nova - Caixa Postal: 1524 CEP: 59072-970 - Natal - RN - Brasil E-mail: mol@gmail.com Telefone: (84) 3215-3536

Magaly Aparecida Galvão Dantas de Melo Mestre em Engenharia da Produção pela Universidade Federal do Rio Grande do Norte Endereço: Rua João Pessoa, 204 - Cidade Alta CEP: $59025-500$ - Natal - RN - Brasil E-mail: magalydantas@hotmail.com Telefone: (84) 3004-3786

Rodolfo Maia Rosado Cascudo Rodrigues Mestre em Ciências Contábeis pela Universidade Federal do Rio Grande do Norte Endereço: Campus Universitário - UFRN, Lagoa Nova - Caixa Postal: 1524 CEP: 59000-000 - Natal - RN - Brasil

E-mail: rmrcr@hotmail.com Telefone: (84) 3215-3486

\footnotetext{
${ }^{1}$ Artigo recebido em 08/04/2017. Revisado por pares em 07/09/2018. Reformulado em 23/11/2018. Recomendado para publicação em 27/11/2018 por Tarcísio Pedro da Silva. Publicado em 20/12/2018. Organização responsável pelo periódico: FURB.
} 


\section{RESUMO}

Este estudo tem por objetivo propor um modelo de medida que ancore os determinantes da aversão à perda em decisões financeiras, tratadas até então de forma parcial e fragmentada. A revisão bibliográfica conduziu ao desenvolvimento de um modelo fatorial confirmatório de segunda ordem com treze variáveis latentes e sessenta e cinco variáveis manifestas. Empregaram-se o método da Máxima Verossimilhança e, como mecanismo de robustez, o método da Distribuição Assintótica Livre, haja vista os desvios da normalidade multivariada encontrada nas variáveis de análise. A amostra deste estudo é não probabilística, formada por estudantes de graduação e profissionais de todo o Brasil, e composta por 9.308 dados válidos para a análise. Adotou-se uma abordagem de validação cruzada e a amostra dividida em duas subamostras com 4.654 observações, denominadas amostra de investigação e amostra de validação. A evidência empírica do modelo teórico foi submetida à amostra de investigação e validada pela amostra de validação. $\mathrm{O}$ modelo empírico de aversão à perda resultante deste trabalho mostrou-se estável e invariante, o que viabiliza e preenche uma lacuna premente na literatura de finanças, a ausência de uma métrica latente consistente da aversão à perda.

Palavras-chaves: Aversão à Perda. Teoria dos Prospectos. Análise Fatorial Confirmatória.

\section{ABSTRACT}

This study aims to propose a measurement model that anchor the determinants of loss aversion in financial decisions, which have been treated in a partial and fragmented way by the academy. The literature review led to the development of a second order confirmatory factorial model with thirteen latent variables and sixty five manifest variables. The maximum likelihood method was used and, as a robustness mechanism, the Free Asymptotic Distribution method, considering the deviations of the multivariate normality found in the analysis variables. The sample of this study is non-probabilistic, formed by undergraduate and professional students from all over Brazil, and composed of 9,308 data valid for the analysis. A cross-validation approach was adopted and the sample divided into two subsamples with 4,654 observations, called the research sample and the validation sample. The empirical evidence of the theoretical model was submitted to the research sample and validated by the validation sample. The empirical model of loss aversion resulting from this work has proved to be stable and invariant, which makes feasible and fills a pressing gap in the finance literature, the absence of a consistent latent metric of loss aversion.

Keywords: Loss Aversion. Prospect Theory. Confirmatory Factor Analysis.

\section{RESUMEN}

Este estudio tiene por objetivo proponer un modelo de medida que ancore los determinantes de la aversión a la pérdida en decisiones financieras, tratadas hasta entonces de forma parcial y fragmentada por la academia. La revisión bibliográfica condujo al desarrollo de un modelo factorial confirmatorio de segundo orden con trece variables latentes y sesenta y cinco variables manifiestas. Se emplearon el método de la Máxima Verosimilitud y, como mecanismo de robustez, el método de la Distribución Asintótica Libre, hay vistas a los desvíos de la normalidad multivariada encontrada en las variables de análisis. La muestra de este estudio es no probabilística, formada por estudiantes de graduación y profesionales de todo Brasil, y compuesta por 9.308 datos válidos para el análisis. Se adoptó un enfoque de validación cruzada y la muestra dividida en dos submuestras con 4.654 observaciones, denominadas muestra de investigación y muestra de validación. La evidencia empírica del modelo teórico fue sometida a la muestra de investigación y validada por la muestra de validación. El modelo empírico de aversión a la pérdida resultante de este trabajo, se mostró estable e invariante, lo que viabiliza 
y llena una laguna urgente en la literatura de finanzas, la ausencia de una métrica latente consistente de la aversión a la pérdida.

Palabras clave: La aversión a la pérdida. Teoría de las Perspectivas. Análisis Factorial Confirmatorio.

\section{INTRODUÇÃO}

A Teoria da Perspectiva implica que o ser humano é avesso a riscos para ganhos e propenso a riscos em situações de perda. Assim, em relação a ganhos, possui preferência pelo ganho tido como certo e evita correr riscos, em um comportamento definido como efeito certeza (certainty effect). Em relação a perdas o indivíduo prefere correr riscos para evitá-la. Essa atitude, de maior sensibilidade a perdas que a ganhos é conhecida como aversão à perda (KAHNEMAN; TVERSKY, 1979; KAHNEMAN; TVERSKY, 1984).

Um dos aspectos básicos da aversão à perda é que o ser humano sente cerca de duas vezes mais a dor ocasionada pela perda do que o prazer ocasionado por um ganho equivalente. Dessa forma, em relação a ganhos, o indivíduo prefere não arriscar e decide por ganhos certos. Já em relação a perdas, como o sentimento de dor é maior, ele decide arriscar-se para evitá-la (ABDELLAOUI et al., 2007; WILLEMSEN; BÖCKENHOLT, 2011). Além disso, sabe-se que a variação da quantidade de dinheiro esperada causa variação na quantidade de prazer ou dor ocasionado (HARINCK et al, 2007).

A partir das evidências empíricas de que o indivíduo é influenciado pela aversão à perda, diversos autores se propuseram a pesquisar sua estrutura (ABELER et al, 2011; BARBERIS, 2012; HARINCK et al, 2007; HOCHMAN; YECHIAM, 2011; KAHNEMAN; TVERSKY, 1979; KAHNEMAN; TVERSKY, 1984; OKADA, 2001; PETERS et al, 2003; SHEFRIN; STATMAN, 1985; THALER, 1980; WOLF et al, 2008). Contudo, esses estudos reportaram as relações e influências sobre a aversão à perda de forma fragmentada e isolada. A literatura ainda é omissa no que se refere ao tratamento dos elementos constitutivos da aversão à perda de forma ampla. Assim sendo, não há nenhuma evidência de pesquisas que se propusessem incorporar os elementos já reportados na literatura em um único modelo teórico-empírico, de modo a subsidiar uma compreensão ampliada do comportamento associado a esse viés.

A principal contribuição desse estudo acerca da aversão à perda é a de compreender a estrutura latente de sua formação a partir das evidências até então produzidas. O desenvolvimento de pesquisas que ampliam o locus de análise para dar conta, em conjunto, de uma classe mais generalizada de evidências é fortemente desafiador e igualmente complexo, sobretudo por não se censurar diante de um único paradigma existente. Dessa forma, o objetivo geral deste trabalho é propor um modelo de medida que incorpore os determinantes da aversão à perda de indivíduos em decisões financeiras. A classe de modelagem de equações estruturais engloba várias técnicas estatísticas para avaliar relações entre as variáveis analisadas, permitindo, assim, realizar análises quantitativas sobre o modelo teórico proposto pelo pesquisador. E no caso específico, a análise fatorial confirmatória de segunda ordem. Nesse sentido, a pesquisa se diferencia das demais, pois procura testar a validade de um modelo teórico multivariado, baseado nas diversas relações bivariadas identificadas na literatura, e considerando todas as variáveis observáveis e latentes, sendo, portanto, necessária a utilização de um modelo de medida latente.

É importante destacar que, assim como este estudo, diversos outros empregaram amostras de estudantes de graduação e profissionais para observar a aversão à perda. É o caso de Kahneman e Tversky (1979), Gollier (2000) e Andrade (2012), para estudantes, e Grable e Lytton (1999), Gachter et al. (2010), Melo e Silva (2010), Wang et al. (2013) e Eiichi et al. (2013). 
Além disso, no Brasil, estudos como o de Basso, Kimura e Krauter (2006), Silva e Araújo (2007), Leone e Guimarães (2013) e Melo e Silva (2010) encontraram divergências em seus resultados quando comparados aos da pesquisa seminal de Kahneman e Tversky (1979) e Kahneman e Tversky (1997).

Nessa perspectiva, a investigação e compreensão da estrutura da aversão à perda e seus fatores característicos determinantes assume papel de vanguarda e fundamental para o avanço das pesquisas sobre finanças comportamentais no Brasil e no mundo.

A aversão à perda representa um dos marcos fundamentais da investigação comportamental em economia e finanças. E, apesar de existirem estudos sobre o tema, desconhecem-se pesquisas nacionais e internacionais que se propuseram a investigar a formação da aversão à perda por meio de um modelo de medida estrutural abrangente. Dessa forma, contribui ainda para o desenvolvimento do tema, já que oferece direcionamentos as pesquisas futuras da aversão à perda.

Considerando, então, os apontamentos citados, tem-se a seguinte questão de pesquisa: quais fatores se mostram relevantes para representar um modelo de medida latente da aversão à perda em decisões financeiras?

Inicialmente, este estudo identificou as variáveis potencialmente relacionadas à aversão à perda, de forma a propor um modelo teórico amplo testado frente à amostra de estudantes de graduação e profissionais de todas as nove áreas de conhecimento do Conselho Nacional de Desenvolvimento Científico e Tecnológico - CNPq.

\section{FUNDAMENTAÇÃO TEÓRICA DO MODELO E DESENVOLVIMENTO DAS HIPÓTESES}

Kahneman e Tversky (1979) explicam que o indivíduo é avesso a perdas. Por consequência, em relação a perdas, corre riscos para evitá-las, o que não ocorre em relação a ganhos, preferindo não correr riscos, optando pelo ganho certo. Em 1992, Tversky e Kahneman revisaram a teoria da perspectiva, acrescentando novas características da aversão à perda. Para os autores, o nível de aversão à perda depende da probabilidade envolvida nas alternativas, quando há alta probabilidade, o comportamento esperado de aversão à perda se confirma, existindo aversão a riscos para ganhos (efeito certeza) e propensão a riscos para evitar perdas (TVERSKY; KAHNEMAN, 1992; KAHNEMAN, 2003; BARBERIS; THALER, 2005; BARBERIS, 2012; LIU et al., 2014; PASQUARIELLO, 2014) (MELO; SILVA, 2010) (BASSO; KIMURA; KRAUTER, 2006). (SILVA; ARAÚJO, 2007) (LEONE; GUIMARÃES, 2013).

Assim, formulam-se as seguintes hipóteses de pesquisa, respectivamente:

Hipótese $1\left(H_{1}\right)$ : "Aversão a riscos para ganhos de alta probabilidade" compõe o nível de aversão à perda, e

Hipótese $2\left(\boldsymbol{H}_{2}\right)$ : Propensão a riscos para perdas de alta probabilidade compõe o nível de aversão à perda.

Na revisão da teoria da perspectiva publicada em 1992, além das características relacionadas à alta probabilidade, citadas no tópico anterior, foram incluídas as relacionadas à baixa probabilidade: propensão a riscos para ganhos e aversão a riscos para perdas. É importante destacar que essas duas características representam uma negação do fenômeno da aversão à perda, quando há baixa probabilidade envolvida (TVERSKY; KAHNEMAN, 1992; KAHNEMAN, 2003; BARBERIS; THALER, 2005; BARBERIS, 2012; LIU et al., 2014; PASQUARIELLO, 2014).

Assim, têm-se as seguintes hipóteses de pesquisa, respectivamente. 
Hipótese $3\left(\boldsymbol{H}_{3}\right)$ : Propensão a riscos para ganhos de baixa probabilidade compõem o nível de aversão à perda, e

Hipótese $4\left(\boldsymbol{H}_{4}\right)$ : Aversão a riscos para perdas de baixa probabilidade compõem o nível de aversão à perda.

Além das características que compõem a aversão à perda, encontradas ao se utilizar valores estáticos, Kahneman e Tversky (1984) e Tversky e Kahneman (1992) explicam que a aversão à perda pode, também, ser observada em mudanças de ganhos e perdas para uma situação melhor ou pior, sempre relacionadas a um ponto de referência pré-estabelecido (KAHNEMAN, 2003; ABELER et al., 2011; KARLE et al., 2013). Esse comportamento é idêntico ao esperado do fenômeno da aversão à perda quando se envolvem altas probabilidades. Essas características foram utilizadas no modelo como duas variáveis latentes: aversão a riscos para ganhos em mudanças e propensão a riscos para perdas em mudanças.

Assim, têm-se as seguintes hipóteses de pesquisa, respectivamente:

Hipótese $5\left(\boldsymbol{H}_{5}\right)$ : “Aversão a riscos para ganhos em mudanças" compõe o nível de aversão à perda, e

Hipótese $6\left(\boldsymbol{H}_{\mathbf{6}}\right)$ : "Propensão a riscos para perdas em mudanças" compõe o nível de aversão à perda.

Proposto por Thaler (1980), o endowment effect estabelece que a aversão à perda é, também, observada em situações que não envolvem riscos. Esse comportamento foi mais tarde confirmado por Knetsch (1989), Kahneman, Knetsch e Thaler (1990), Putler (1992), Carmon e Ariely (2000) e Levin et al. (2002). Galin (2012) investigou o endowment effect sob dois aspectos: em decisões de grupo e individualmente. Os resultados mostraram que o efeito foi identificado nos dois aspectos, mas com maior nível de intensidade quando as decisões foram tomadas em grupo. Já Nash e Rosenthal (2014) investigaram o endowment effect em simulações de loteria com prêmios de habitação, produto de alto valor, e mostraram que o efeito se mostra persistente e aumenta com a experiência adquirida.

Dessa forma, formula-se a seguinte hipótese de pesquisa:

Hipótese $7\left(\boldsymbol{H}_{7}\right)$ : "Diferença entre preços de venda e de compra" contribue para o nível de aversão à perda.

Harinck et al. (2007) descobriram que o fenômeno da aversão à perda se inverte não apenas quando há baixa probabilidade, como defendido por Tversky e Kahneman (1992), mas, também, quando as alternativas envolvem pequenas quantias (até 5,00 Euros). Nesses casos, o prazer por ganhar é maior que a dor por perder e a aversão à perda só se manifesta adequadamente a partir de cerca de 50 Euros.

Já Blavatskyy e Pogrebna (2007) identificaram que a aversão à perda é frequentemente violada em situações que envolvem altas quantias. Na pesquisa, $73 \%, 47 \%$ e $43 \%$ dos franceses, italianos e britânicos, respectivamente, violaram a aversão à perda em alternativas com altas quantias. Erev et al. (2008) investigaram a diminuição da sensibilidade à aversão à perda de acordo com a experiência adquirida em escolhas. Os resultados confirmaram essa hipótese e mostraram uma diminuição do nível de aversão à perda relacionada à diminuição da magnitude nominal, o que é semelhante aos resultados encontrados por Harinck et al. (2007).

Dessa forma formulam-se as seguintes hipóteses de pesquisa, respectivamente. 
Hipótese $8\left(\boldsymbol{H}_{\mathbf{8}}\right)$ : Trade-off do prazer de ganhar e a dor por perder pequenas quantias contribue para o nível de aversão à perda.

Hipótese $9\left(\boldsymbol{H}_{\mathbf{9}}\right)$ : Trade-off do prazer de ganhar e dor por perder altas quantias contribue para o nível de aversão à perda.

Shefrin e Statman (1985) explicam que a aversão à perda é responsável pela característica de o indivíduo vender um título rapidamente quando se observa ganhos e tardar a negociar quando se observa perdas, em um fenômeno denominado efeito disposição (disposition effect). Esse comportamento contraria a lógica da maximização dos resultados econômicos, segundo o qual a decisão deveria ser inversa. Odean (1998) investigou os dados de 10 mil contas de corretagem da NYSE, AMEX e Nasdaq para verificar a existência do efeito disposição. Os resultados do trabalho mostram que os investidores relutam em negociar seus ativos quando há perdas e vendem rapidamente quando há ganhos.

Da Costa et al. (2013) investigaram o efeito disposição e sua persistência em participantes com e sem experiência de mercado, através de um experimento de laboratório. Além de identificar o viés nos participantes, verificaram que os mais experientes são menos afetados pelo efeito que os menos experientes. Já Rau (2014) investigou o efeito disposição com intuito de observar diferenças entre homens e mulheres. Concluiu que as mulheres são mais influenciadas por esse desvio que os homens.

Assim, têm-se as seguintes hipóteses de pesquisa, respectivamente:

Hipótese $10\left(\boldsymbol{H}_{\mathbf{1 0}}\right)$ : Efeito Disposição para Ganhos forma o nível de aversão à perda.

Hipótese $11\left(\boldsymbol{H}_{11}\right)$ : Efeito Disposição para Perdas forma o nível de aversão à perda.

Okada (2001) investigou a disposição do consumidor em atualizar seus bens duráveis através de um questionário aplicado a estudantes de graduação e pós-graduação. Os resultados indicam que a decisão de comprar ou substituir um bem durável sofre influência de fatores econômicos e psicológicos, como consequência da aversão à perda. Os indivíduos criam um valor mental para os ativos e sua baixa ou substituição pode ser algo doloroso, o que pode causar relutância em atualizá-los.

$\mathrm{O}$ autor afirma, ainda, que o indivíduo substitui mais facilmente um bem antigo por um novo quando o bem antigo é recebido como parte do pagamento do novo. Dessa forma, o comprador interpreta que não existe desperdício na negociação e que é uma transação vantajosa. Novemsky e Kahneman (2005) explicam que a aversão à perda pode ser observada em casos de negociação de bens duráveis em que os vendedores sentem a dor da perda ao ter que atualizar esse bem. Nesses casos, o indivíduo projeta a venda do bem não em termos de benefício, já que será substituído por outro, mas em termos de perda. A explicação para tal atitude é o valor mental e psicológico que o indivíduo tende a atribuir aos bens que possui.

Assim tem-se a seguinte hipótese de pesquisa.

Hipótese $12\left(\boldsymbol{H}_{12}\right)$ : Apego a Bens Materiais contribuem para formação do nível de aversão à perda.

Strahilevitz e Loewenstein (1998) verificaram os efeitos do tempo de posse de ativos em sua avaliação e observaram que o passado do objeto pode influenciar a avaliação do proprietário. Para ativos que atualmente estejam sob a sua posse, os indivíduos acrescentam ao valor do objeto um valor histórico, representado pelo tempo de posse do objeto. Assim, a 
aversão à perda se acumularia de acordo com o tempo de posse do ativo. Em sua pesquisa, os autores observaram que os participantes que ficavam mais tempo com o bem utilizado no experimento (xícara de café) exigiram valores maiores pela venda do bem do que os que o possuíam há menos tempo.

Wolf et al (2008) explicam que a tendência de o indivíduo valorizar os itens que possui atualmente e possuiu no passado faz parte de um fenômeno denominado efeito de comprimento de propriedade. Em seu estudo, os autores utilizaram um experimento de laboratório com canecas de café e verificaram que em todos os casos o contato físico (posse) com o objeto influenciou positivamente a valorização desse item. Já Kogut e Kogut (2011) argumentam que estilos de apego individuais podem contribuir para a valorização de um bem pelo tempo de posse. Assim, da mesma forma que o indivíduo pode ter medo de perder alguém, pode estender esse medo aos seus bens, em níveis variados.

Dessa forma, formula-se a seguinte hipótese de pesquisa:

Hipótese $13\left(\boldsymbol{H}_{13}\right)$ : Acumulação pelo tempo de posse colabora para formação do nível de aversão à perda.

\section{METODOLOGIA DE PESQUISA}

A pesquisa é de abrangência nacional com utilização de procedimento amostral, em dois grupos distintos, formados por estudantes de graduação e profissionais das nove áreas de conhecimento do Conselho Nacional de Desenvolvimento Científico e Tecnológico - CNPq.

O modelo de base da investigação está ancorado na Análise Fatorial Confirmatória AFC. Embora apresente um composto teórico próprio ancoram-se, stricto sensu, à Modelagem de Equações Estruturais pelas características comuns de análise do modelo de medida. Por se tratar de uma investigação ainda não observada no que refere a integração de construtos para formação da variável de segunda ordem "Aversão a perda", foi necessário a implementação de uma investigação do tipo "double response" que pudesse conferir análise e validação da análise. Neste sentido a Análise Fatorial Confirmatória, em seu estado mais puro, é uma forma de validação do modelo teórico proposto. Neste, o modelo é especificado antes mesmo de os dados serem coletados, evitando, assim, que possam influenciar a estrutura inicial do modelo.

De toda forma, a classe de modelos com variáveis latentes invariavelmente recai no composto de análises de equações estruturais (entendido aqui como uma classe de modelo mais amplo de análise - modelo de medida mais o modelo estrutural). Adicionado à questão, a necessidade de construção de um modelo flexível que possa capturar comunalidades adjacentes à aversão a perda, a partir de um conjunto de constructos latentes de $1^{a}$ ordem, convergiu de forma natural para a escolha das ferramentas que apropriam destas características, a exemplo da Análise Fatorial Confirmatória.

A AFC foi produzida a partir da matriz de covariâncias e AFE a partir da modelagem por meio da matriz de correlações. Em especial a AFC segue a abordagem da covariância utilizando-se do método de máxima verossimilhança e modelo de distribuição assintótica livre (mínimos quadrados ponderados) que buscam comparar a matriz empírica e saturada por meio do teste de qui-quadrado de forma a ponderar sobre a sua semelhança estatística, diferentemente dos métodos por meio dos quadrados parciais. Todos os demais testes (CFI, TLI, GFI, RMSEA, etc.) decorrem do teste inicial do qui-quadrado.

\subsection{Instrumento e Procedimentos de Coleta de Dados}

O instrumento de pesquisa utilizado foi um questionário, desenvolvido a partir da revisão bibliográfica. A revisão de literatura conduziu à definição de 13 variáveis latentes 
formadoras da aversão à perda, cada um com cinco variáveis manifestas, resultando em um survey com 65 questões.

A quantidade de questões propostas como variáveis manifestas observam a necessidade de garantir, de um lado, que a estrutura de equações sejam sobreidentificadas e, ao mesmo tempo, garantam baixa probabilidade de sobreidentificação empírica, problemas de convergência e variâncias negativas. Na Análise Fatorial Confirmatória e Modelagem de Equações Estruturais as variâncias são estimadas assintoticamente. Assim, se por um lado a grande quantidade de variáveis manifestas concorre para a sobreidentificação do sistema de equações, por outro lado eleva as probabilidades de redundância que, em última análise, concorrerão para produção de matrizes não definida-positivas e variâncias negativas decorrentes de multicolinearidades severas. Multicolinearidades essas muito comuns em instrumentos de pesquisa do tipo survey. Isto posto, após ensaios pilotos, reconfigurações de instrumentos e análises marginais sobre comunalidades e singularidades das variáveis manifestas sobre a amostra piloto conseguiu-se produzir um instrumento confiável e válido, a partir de quantidades equivalentes de variáveis manifestas, tornando o instrumento com menor probabilidade de redundância e permitindo a execução de um sistema sobreidentificado.

Como forma de verificar a adequação do questionário e sua capacidade de captar os fenômenos observados, um pré-teste foi executado de forma pessoal e forma acidental, a 356 alunos dos cursos de Ciências Contábeis e Administração da Universidade Federal do Rio Grande do Norte - UFRN. A análise preliminar do questionário ensejou alteração no instrumento, haja vista a incapacidade de algumas questões não conseguir níveis adequados de confiabilidade interna e extrair com segurança os fenômenos propostos.

A observação dos resultados do pré-teste e dos comentários dos respondentes mostrou que algumas questões não estavam apresentadas de forma clara, sendo essa a principal correção realizada. Um segundo pré-teste foi realizado e, desta vez, os resultados mostraram que as falhas foram corrigidas.

O questionário utilizou uma escala tipo likert, de 1 a 11 pontos, sendo 1 para "discordo totalmente" e 11 para "concordo totalmente". A escala transformada de onze níveis se justifica por permitir maior grau de liberdade ao respondente, tornando possível p-valores confiáveis para testes estatísticos quantitativos (GLASS et al, 1972; CARIFIO; PERLA, 2007). A amostra utilizada nessa pesquisa é não probabilística. O questionário foi abrigado no Google docs. Em relação aos profissionais, os autores mantiveram contato com os diversos conselhos de classe, associações, sindicatos e sociedades profissionais nacionais solicitando o envio do link de pesquisa abrigado no google docs para os profissionais filiados. Em relação aos estudantes, o pesquisador entrou em contato via telefone e $e$-mail com as pró-reitorias de graduação de no mínimo três universidades federais por região, mais o Distrito Federal, totalizando 21 instituições de ensino superior, solicitando apoio na viabilização da pesquisa. As IES então retransmitiam a seus alunos a mensagem explicativa da pesquisa junto ao link que conduzia ao questionário de pesquisa. As questões foram elaboradas pelos pesquisadores e um exemplo de como foram apresentadas pode ser observada a seguir (para uma escala de 1 a 11).

Tabela 1. Dados válidos coletados seccionados por ocupação e região

\begin{tabular}{ccccccc}
\hline Região & Estudantes & Percentual & Profissionais & Percentual & Total & Percentual \\
\hline Centro-Oeste & 3.018 & $39,90 \%$ & 423 & $21,27 \%$ & 3.441 & $36,02 \%$ \\
\hline Nordeste & 2.848 & $37,65 \%$ & 640 & $32,18 \%$ & 3.488 & $36,51 \%$ \\
\hline Sudeste & 1.412 & $18,67 \%$ & 793 & $39,87 \%$ & 2.205 & $23,08 \%$ \\
\hline Norte & 192 & $2,54 \%$ & 83 & $4,17 \%$ & 275 & $2,88 \%$ \\
\hline Sul & 94 & $1,24 \%$ & 50 & $2,51 \%$ & 144 & $1,51 \%$ \\
\hline Total & $\mathbf{7 . 5 6 4}$ & $\mathbf{1 0 0 , 0 0 \%}$ & $\mathbf{1 9 8 9}$ & $\mathbf{1 0 0 , 0 0 \%}$ & $\mathbf{9 . 5 5 3}$ & $\mathbf{1 0 0 , 0 0 \%}$ \\
\hline
\end{tabular}

Fonte: Dados da pesquisa (2014) 
Eu prefiro ter agora um ganho certo de $R \$ 3.000$ a ter $80 \%$ de chance de ganhar $R \$ 3.800$ e $20 \%$ de não ter ganhos.

Foram coletadas 9.553 observações válidas. A tabela 1 apresenta o total de dados coletados, seccionados por estudantes e profissionais e por região.

A tabela 2 apresenta a frequência de gênero dos participantes da pesquisa.

Tabela 2. Frequência do gênero dos participantes

\begin{tabular}{ccc}
\hline & Quantidade & Percentual \\
\hline Masculino & 4.753 & $49,8 \%$ \\
\hline Feminino & 4.800 & $50,2 \%$ \\
\hline Total & $\mathbf{9 5 5 3}$ & $\mathbf{1 0 0 , 0 \%}$ \\
\hline
\end{tabular}

Fonte: Dados da pesquisa (2014)

A tabela 2 mostra que dos 9.553 dados válidos, 4.753 (49,8\%) são do gênero feminino e $4.800(50,2 \%)$ são do gênero masculino. Pelo fato de a amostra ser considerada suficientemente densa, não foi necessário utilizar procedimentos de reamostragem, como o bootstrap. A tabela 3 apresenta a frequência de idade dos respondentes. O mais novo tinha 16 anos na data da coleta e o mais velho 67 anos.

Tabela 3. Frequência da idade dos participantes

\begin{tabular}{ccc}
\hline Faixa & Quantidade & Percentual \\
\hline $\mathbf{1 6}$ a 21 & 3.773 & $39,50 \%$ \\
\hline $\mathbf{2 2}$ a 27 & 3.602 & $37,71 \%$ \\
\hline $\mathbf{2 8}$ a 33 & 1.214 & $12,71 \%$ \\
\hline $\mathbf{3 4}$ a 39 & 468 & $4,90 \%$ \\
\hline $\mathbf{4 0}$ a 45 & 234 & $2,45 \%$ \\
\hline $\mathbf{4 6}$ a $\mathbf{5 1}$ & 161 & $1,69 \%$ \\
\hline $\mathbf{5 2}$ a 57 & 74 & $0,77 \%$ \\
\hline $\mathbf{5 8}$ a 63 & 23 & $0,24 \%$ \\
\hline $\mathbf{6 4}$ a 67 & 4 & $0,04 \%$ \\
\hline Total & $\mathbf{9 . 5 5 3}$ & $\mathbf{1 0 0 , 0 0 \%}$ \\
\hline
\end{tabular}

Fonte: Dados da pesquisa (2014).

A tabela 4 mostra a frequência do grau de instrução dos respondentes.

Tabela 4. Frequência do grau de instrução dos participantes

\begin{tabular}{ccc}
\hline Nível de Instrução & Quantidade & Percentual \\
\hline Estudante de graduação & 7.564 & $79,18 \%$ \\
\hline Graduação completa & 857 & $8,97 \%$ \\
\hline Especialização & 469 & $4,91 \%$ \\
\hline Mestrado & 544 & $5,69 \%$ \\
\hline Doutorado & 119 & $1,25 \%$ \\
\hline Total & $\mathbf{9 . 5 5 3}$ & $\mathbf{1 0 0 , 0 0 \%}$ \\
\hline
\end{tabular}

Fonte: Dados da pesquisa (2014).

A tabela 5 apresenta a frequência da região de origem dos pesquisados. 
DETERMINANTES DA AVERSÃO À PERDA EM DECISÕES FINANCEIRAS: UMA INVESTIGAÇÃO POR MEIO DE MODELOS FATORIAIS

Tabela 5. Frequência da região de origem dos participantes

\begin{tabular}{ccc}
\hline Região & Frequência & Percentual \\
\hline Norte & 275 & $2,88 \%$ \\
\hline Nordeste & 3.488 & $36,51 \%$ \\
\hline Centro-Oeste & 3.441 & $36,02 \%$ \\
\hline Sudeste & 2.205 & $23,08 \%$ \\
\hline Sul & 144 & $1,51 \%$ \\
\hline Total & $\mathbf{9 . 5 5 3}$ & $\mathbf{1 0 0 , 0 \%}$ \\
\hline
\end{tabular}

Fonte: Dados da pesquisa (2014).

A tabela 6 mostra a frequência da área de conhecimento do CNPq.

Tabela 6. Frequência da área de conhecimento CNPq

\begin{tabular}{ccc}
\hline Área de conhecimento & Quantidade & Percentual \\
\hline Ciências Exatas e da Terra & 1.120 & $11,72 \%$ \\
\hline Ciências Biológicas & 433 & $4,53 \%$ \\
\hline Engenharias & 1.349 & $14,12 \%$ \\
\hline Ciências da Saúde & 1.328 & $13,90 \%$ \\
\hline Ciências Agrárias & 388 & $4,06 \%$ \\
\hline Ciências Sociais Aplicadas & 2.300 & $24,08 \%$ \\
\hline Ciências Humanas & 977 & $10,23 \%$ \\
\hline Linguística, Letras e Artes & 746 & $7,81 \%$ \\
\hline Outros & 912 & $9,55 \%$ \\
\hline Total & $\mathbf{9 . 5 5 3}$ & $\mathbf{1 0 0 , 0 0 \%}$ \\
\hline
\end{tabular}

Fonte: Dados da pesquisa (2014).

Os dados obtidos foram inspecionados de forma a verificar os pressupostos da abordagem de modelos de covariância (utilizados na AFC). Assim, por meio do boxplot identificou-se 245 observações extremas (outliers) que foram excluídas da análise.

\subsection{Verificação de Pressupostos da Modelagem de Equações Estruturais}

Como forma de evitar a possível tendência de alguns participantes responderem da mesma forma as questões que pertencem ao mesmo fator, optou-se por separar as questões da mesma variável latente, de forma a não ficarem agrupadas no questionário. Assim, as cinco questões por variável latente foram distribuídas no questionário, aleatoriamente, e a primeira providência adotada após a coleta de dados foi o reagrupamento das variáveis manifestas por fator.

Para avaliar a confiabilidade do instrumento de medida, foi utilizado o teste Alfa de Cronbach, que mede em uma escala de 0 a $1(0<\alpha<1)$ a consistência interna de um questionário aplicado. Marôco (2006) defende que, para alguns cenários nas ciências sociais, um alfa acima de 0,6 é aceitável, desde que os resultados sejam interpretados com alguma precaução. Dos 13 fatores utilizados, 11 apresentaram boa ou muito boa consistência do instrumento de pesquisa. Entretanto, dois fatores (12 e 13) apresentaram baixa confiabilidade, porém, esse resultado não invalida o uso desses fatores, já que se considera aceitável um alfa acima de 0,6 para as ciências sociais e tendo em conta que o alfa do instrumento inteiro foi de 0,798 .

Em relação ao pressuposto de normalidade multivariada nas variáveis manifestas, Marôco (2010) se apropria de ensaios conduzidos por West et al (1995), Curran et. al (1996), Kline (2004, pp.82-83) e Finney e Distefano (2006, pp. 272-273) e aponta de que apenas a 
violação severa do pressuposto da normalidade multivariada, conduziria restrições ao uso do método de máxima verossimilhança. No entanto, ao se observar os valores absolutos de assimetria $(s k)$ e curtose $(k u)$ constata-se que não houve violação séria do pressuposto de normalidade, de forma a ensejar estruturas de estimação não clássicas. A referência utilizada por Kline (2004) e Finney e Distefano (2006), para generalizar desvios suaves de normalidade multivariada, utilizam scores de assimetria sk inferiores a 2 e os de curtose $k u$ inferiores a 7. Como foi constatado que os dados são suavemente não normais (com scores de assimetria e curtose abaixo dos referenciais supracitados), mesmo sem violação séria do pressuposto de normalidade, optou-se por utilizar dois métodos de discrepância na análise fatorial confirmatória: a máxima verossimilhança (que exige a normalidade dos dados ou aproximadamente normais) e a distribuição assintótica livre (ADF - em que não há exigência de normalidade dos dados). Entretanto, não houve diferença de resultado entre as duas técnicas utilizadas.

A estratégia utilizada busca testar a robustez do método da máxima verossimilhançaML pelo emprego do método da Distribuição Assintótica Livre-ADF (Método dos Mínimos Quadrados Ponderados). Isso porque o método ML é o mais aplicado e tradicional nos estudos da AFC e SEM. Embora o método de ADF contorne os desvios de curtose na matriz de variância-covariância por meio de sua função de discrepância, é um método pouco parcimonioso e complexo que eleva a dimensão da matriz de variância-covariância, exponencialmente, exigindo amostras essencialmente elevadas ( $\mathrm{n}>6500$ observações), de forma a evitar problemas com convergência numérica e singularidades. De qualquer forma, sendo possível assumir validade da distribuição (aproximadamente) normal das variáveis manifestas exigida pelo método ML, o mainstrean da modelagem de modelos de covariância advoga para seu uso indicando que os desvios da normalidade em sendo sutil, tem pouco impacto sobre os resultados da análise. Assim sendo, o uso solo da distribuição ADF acontece quando há sério desvio da normalidade multivariada dos dados. Mesmo sendo possível a utilização do ML em razão de um desvio marginal da assimetria e curtoses individuais das variáveis manifestas, os pontos de corte apresentado por West et al (1995), Curran et. al (1996), Kline (2004, pp.82-83) e Finney e Distefano (2006, pp. 272-273), são apenas referenciais, não permitindo um ponto de corte objetivo. Assim sendo, nesta investigação buscou-se aplicar as duas distribuições como análise complementar de forma a testar a consistência e convergência dos resultados (análise de robustez).

Apenas duas variáveis violaram o pressuposto de ausência de multicolinearidade, Q42 $(14,108)$ e Q43 (11,685), com valores VIF maiores que 10. Hair et al. (2005) indicam ações corretivas quando é verificada multicolinearidade. Entre elas há a opção de eliminar uma ou mais variáveis com alta correlação. Assim, seguindo o sugerido pelo autor, optou-se por excluir a variável Q42 da análise, a que possuía maior VIF.

Após a eliminação de Q42, todas as variáveis manifestas apresentaram VIF inferior a 10, inclusive a Q43, que teve seu VIF reduzido a 8,172. Dessa forma, como consequência da presença de multicolinearidade, a variável Q42 não será utilizada nos modelos de análise fatorial. Importante destacar que todos os pressupostos para modelagem indicados por Hair et al. (2005) foram atendidos.

\subsection{Modelo Teórico Proposto}

Kahneman (2000) explica que prazer e dor são, na verdade, fatores de um momento específico que geram experiência. Mas, os indivíduos tendem a valorizar e estender os efeitos da dor por um longo tempo. Assim, a ocorrência de prazer ou dor e sua intensidade dependem da utilidade do episódio ou objeto para o indivíduo, podendo ser mais ou menos prazeroso ou doloroso. 
Além disso, para o autor a intensidade de prazer e dor depende de características pessoais, tais como, expectativa e experiência. Assim, argumenta que a utilidade depende de quatro características: a decisão inferida a partir das preferências observadas, a crença sobre a utilidade futura, a utilidade atual baseada no momento e a utilidade que se baseia em avaliações retrospectivas de períodos passados.

Embora fosse esperado que dor e prazer fossem medidas negativas e positivas de níveis equivalentes, quando as situações envolvessem um mesmo objeto nas mesmas condições, Kahneman e Tversky (1979) mostram que a dor da perda impacta mais o ser humano do que o prazer de um ganho equivalente, em uma relação de cerca de duas vezes.

Os conceitos que formam o corpo teórico da aversão à perda serviram para a definição das variáveis do modelo. O processo de modelagem, por meio da análise fatorial confirmatória, visa testar a validade empírica de modelos de medida concebidos no âmbito teórico (MARÔCO, 2010).

O modelo construído tem o objetivo de descrever o conjunto de dimensões relatadas na academia que, direta ou indiretamente, importam aversão à perda. Para esse propósito será empregada a análise fatorial exploratória, para identificação do modelo de medida empírico, e análise fatorial confirmatória, para validade do modelo conceitual.

Tabela 7. Variáveis latentes potencialmente relacionadas à aversão à perda

\begin{tabular}{|c|c|c|c|}
\hline Ordem & Variável Latente & $\begin{array}{l}\text { Hipótese de Pesquisa } \\
\text { (relação com a } \\
\text { aversão à perda) }\end{array}$ & Autor/Trabalho base \\
\hline 1 & $\begin{array}{l}\text { Aversão a riscos para ganhos de alta } \\
\text { probabilidade }\end{array}$ & $\mathrm{H}_{1}$ & \multirow{6}{*}{$\begin{array}{l}\text { Kahneman e Tversky (1979); } \\
\text { Kahneman e Tversky (1984); } \\
\text { Kahneman e Tversky (1991); Tversky } \\
\text { e Kahneman (1992); Kahneman } \\
\text { (2003); Barberis e Thaler (2005); } \\
\text { Abeler et al. (2011); Barberis (2012); } \\
\text { Karle et al. (2013); Liu et al. (2014); } \\
\text { Pasquariello (2014) }\end{array}$} \\
\hline 2 & $\begin{array}{l}\text { Propensão a riscos para perdas de } \\
\text { alta probabilidade }\end{array}$ & $\mathrm{H}_{2}$ & \\
\hline 3 & $\begin{array}{l}\text { Propensão a riscos para ganhos de } \\
\text { baixa probabilidade }\end{array}$ & $\mathrm{H}_{3}$ & \\
\hline 4 & $\begin{array}{l}\text { Aversão a riscos para perdas de } \\
\text { baixa probabilidade }\end{array}$ & $\mathrm{H}_{4}$ & \\
\hline 5 & $\begin{array}{l}\text { Aversão a riscos para ganhos em } \\
\text { mudanças para melhor }\end{array}$ & $\mathrm{H}_{5}$ & \\
\hline 6 & $\begin{array}{l}\text { Propensão a riscos para perdas em } \\
\text { mudanças para pior }\end{array}$ & $\mathrm{H}_{6}$ & \\
\hline 7 & $\begin{array}{l}\text { Divergência entre preços de } \\
\text { compra e de venda }\end{array}$ & $\mathrm{H}_{7}$ & $\begin{array}{l}\text { Thaler (1980); Knetsch (1989); } \\
\text { Kahneman, Knetsch, e Thaler (1990); } \\
\text { Putler (1992); Carmon e Ariely } \\
\text { (2000); Levin et al. (2002); Maddux et } \\
\text { al. (2010); Galin (2012); Nash e } \\
\text { Rosenthal (2014) }\end{array}$ \\
\hline 8 & $\begin{array}{l}\text { Prazer por ganhar maior que a dor } \\
\text { por perder - Pequenas quantias }\end{array}$ & $\mathrm{H}_{8}$ & \multirow{2}{*}{$\begin{array}{l}\text { Harinck et al. (2007); Blavatskyy e } \\
\text { Pogrebna (2007); Erev et al. (2008) }\end{array}$} \\
\hline 9 & $\begin{array}{l}\text { Prazer por ganhar se aproxima da } \\
\text { dor por perder - Altas quantias }\end{array}$ & $\mathrm{H}_{9}$ & \\
\hline 10 & Efeito disposição para ganhos & $\mathrm{H}_{10}$ & \multirow{2}{*}{$\begin{array}{l}\text { Shefrin e Statman (1985); Odean } \\
\text { (1998); Da Costa et al. (2013); Rau } \\
\text { (2014) }\end{array}$} \\
\hline 11 & Efeito disposição para perdas & $\mathrm{H}_{11}$ & \\
\hline 12 & Apego a bens materiais & $\mathrm{H}_{12}$ & $\begin{array}{l}\text { Okada (2001); Novemsky e } \\
\text { Kahneman (2005); Maddux et al. } \\
(2010)\end{array}$ \\
\hline 13 & $\begin{array}{l}\text { Acumulação da aversão à perda } \\
\text { por tempo de posse do ativo }\end{array}$ & $\mathrm{H}_{13}$ & $\begin{array}{l}\text { Strahilevitz e Loewenstein (1998); } \\
\text { Wolf et al (2008); Kogut e Kogut } \\
\text { (2011) }\end{array}$ \\
\hline
\end{tabular}

Fonte: Dados da pesquisa (2014). 
Clayton L. L. de Melo - Anderson L. R. Mól - Magaly A. G. D. de Melo - Rodolfo M. R. C. Rodrigues

Figura 1. Modelo Proposto de Aversão à Perda

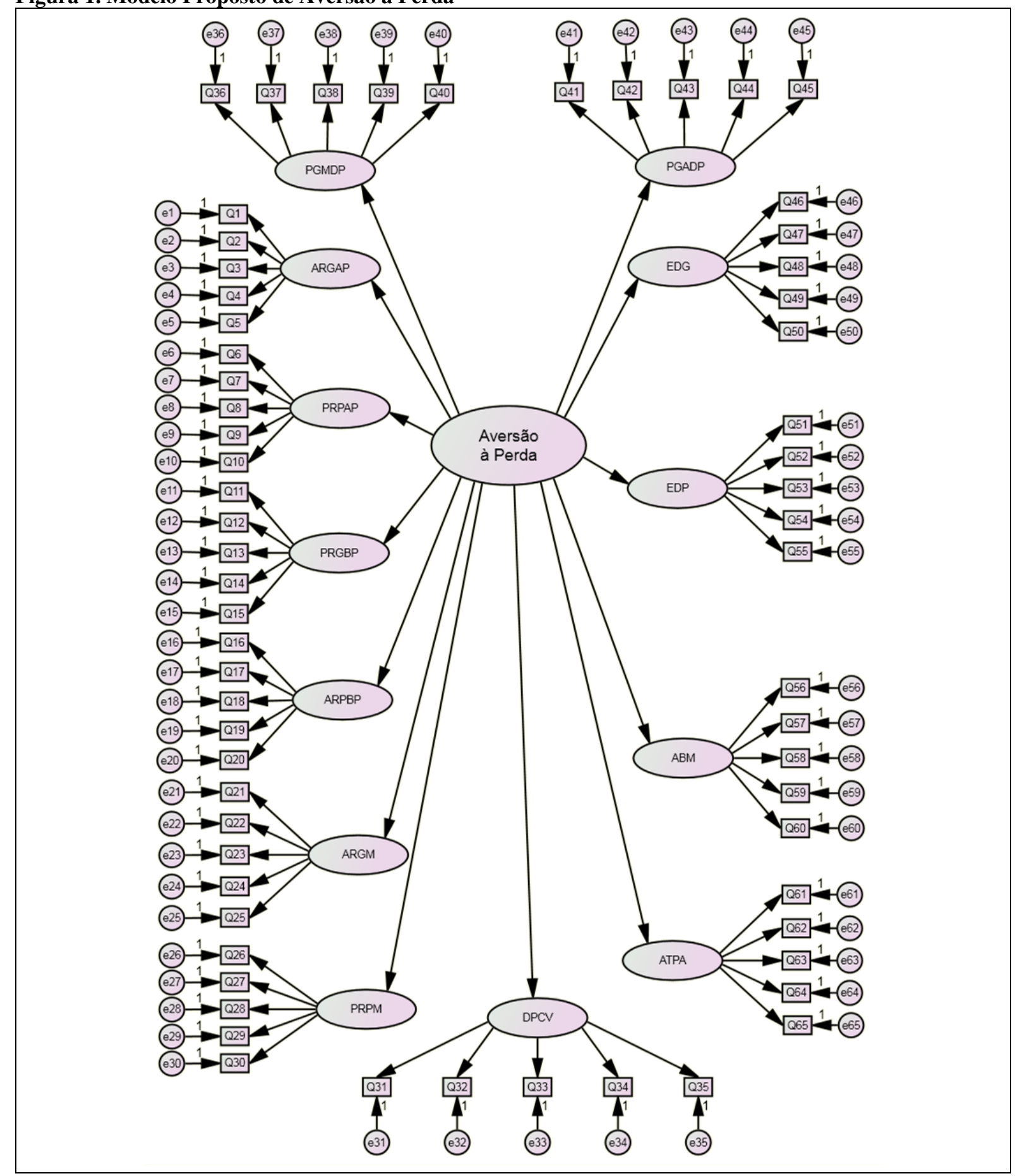

ARGAP $=$ aversão a riscos para ganhos de alta probabilidade; PRPAP $=$ propensão a riscos para perdas de alta probabilidade; $\mathrm{PRGBP}=$ propensão a riscos para ganhos de baixa probabilidade; $\mathrm{ARPBP}=$ aversão a riscos para perdas de baixa probabilidade; ARGM = aversão a riscos para ganhos em mudanças para melhor; PRPM = propensão a riscos para perdas em mudanças para pior; DPCV = divergência entre preços de compra e de venda; PGMDP = prazer por ganhar maior que a dor por perder - pequenas quantias; PGADP = prazer por ganhar se aproxima da dor por perder - altas quantias; $\mathrm{EDG}=$ efeito disposição para ganhos; $\mathrm{EDP}=$ efeito disposição para perdas; $\mathrm{ABM}=$ apego a bens materiais; $\mathrm{ATPA}$ = acumulação da aversão à perda por tempo de posse do ativo Fonte: Dados da pesquisa (2014). 
A revisão teórica realizada conduziu à construção de 13 construtos potencialmente relacionados. Esses construtos partiram da observação dos trabalhos seminais acerca da aversão à perda e de trabalhos complementares que investigaram características diversas que formam o corpo de evidências da aversão à perda.

Por se tratar de um modelo teórico inédito, a determinação das variáveis manifestas se baseou em pesquisa bibliográfica internacional, de forma a levantar as variáveis latentes potencialmente relacionadas à aversão à perda. A proposição do arquétipo dedicado à aversão a perda foi gerada a partir das diferentes evidências já apresentadas e postas na academia mundial. Isto posto, as variáveis latentes foram articuladas de forma conjunta para composição do modelo geral de aversão a perda. A tabela 7 apresenta as variáveis que serão utilizadas nesse estudo, como componentes da aversão à perda.

A tabela 7 evidencia as variáveis e as principais referências utilizadas na determinação do modelo. Para cada uma das 13 variáveis latentes serão utilizadas cinco variáveis manifestas, criadas especificamente para este estudo, como forma de captar os comportamentos discriminados, totalizando 65 questões utilizadas. Os fatores gerados seguem a ordem da formulação das hipóteses.

Já a figura 1 apresenta as 13 variáveis relacionadas, utilizadas no modelo fatorial confirmatório de segunda ordem, na forma de um diagrama de trajetórias.

O modelo teórico pode e deve esboçar as relações esperadas dos construtos. Entretanto, utilizamos a $\mathrm{AFC}$ de segunda ordem para compor o modelo geral de Aversão à Perda. Assim, espera-se que todos os construtos de $1^{\text {a }}$ ordem reproduzam comunalidades relevantes de forma a compor a variável de Aversão a Perda. Neste sentido, os efeitos indiretos (entre os construtos) embora se situem dentro de um mesmo espectro psicométrico, promovem redundâncias indesejáveis na construção da variável de segunda ordem, posto que é observado (no modelo reespecificado) pelas covariâncias entre erros de diferentes constructos. De partida, é impossível elencar a natureza dessas relações, pois seus efeitos se sobrepõem aos erros de medida inevitáveis às pesquisas do tipo survey.

\section{RESULTADOS E ANÁLISE}

Para a etapa de análise de dados, optou-se pela utilização da técnica estatística denominada validação cruzada (cross validation), em que a amostra coletada é subdivida em dois ou mais subconjuntos mutuamente exclusivos, que possuam ou não a mesma quantidade de observações (MALHOTRA, 2004). Após essa divisão, o modelo do estudo é construído com base na primeira subamostra, denominada amostra de análise, e a segunda subamostra, denominada amostra de validação, é utilizada para testar a validade do modelo construído com base na primeira (SCHAPIRE; SINGER, 2000). O uso dessa técnica permitirá observar se o modelo de aversão à perda se mantém estável para as duas amostras estudadas, sendo bastante utilizada em estudos que envolvem pesquisas do tipo survey. A composição das duas amostras foi realizada de forma aleatória.

\subsection{Análise da Amostra 1 - Amostra de Análise}

Neste estudo, a amostra de dados válidos foi dividida em dois subgrupos, cada uma com 4.654 observações. A amostra de análise, para a validação do modelo teórico proposto de aversão à perda, e a amostra de validação, utilizada para verificar a estabilidade dos resultados da análise.

\subsubsection{Resultados da Análise Fatorial Exploratória (AFE) da Amostra de Análise}

A análise fatorial exploratória foi utilizada como forma de verificar a priori a validade dos fatores de $1^{\text {a }}$ ordem e suas relações com as variáveis manifestas. Como o desenvolvimento 
Clayton L. L. de Melo - Anderson L. R. Mól - Magaly A. G. D. de Melo - Rodolfo M. R. C. Rodrigues

do modelo teórico proposto na figura 1 foi baseado em conhecimentos prévios de uma teoria existente, a análise fatorial exploratória foi utilizada para investigar apenas o grau de associação

Tabela 8. Resultados da análise fatorial exploratória dos 13 fatores - amostra 1

\begin{tabular}{|c|c|c|c|c|c|c|c|c|}
\hline \multirow[b]{2}{*}{ 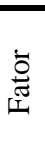 } & \multirow[b]{2}{*}{$\begin{array}{l}\text { Variável } \\
\text { manifesta }\end{array}$} & \multirow[b]{2}{*}{$\begin{array}{c}\text { Comuna- } \\
\text { lidades }\end{array}$} & \multirow[b]{2}{*}{$\begin{array}{c}\text { Carga } \\
\text { fatorial }\end{array}$} & \multirow{2}{*}{$\begin{array}{l}\text { Kaiser- } \\
\text { Meyer- } \\
\text { Olkin } \\
(\text { KMO) }\end{array}$} & \multirow[b]{2}{*}{$\begin{array}{l}\text { Teste de } \\
\text { esfericidade } \\
\text { de Barlett }\end{array}$} & \multicolumn{2}{|c|}{ Matriz anti-imagem } & \multirow[b]{2}{*}{$\begin{array}{c}\text { Variância tota } \\
\text { explicada - } \\
\text { Autovalor }>1\end{array}$} \\
\hline & & & & & & $\begin{array}{l}\text { Média do } \\
\text { MSA }\end{array}$ & $\begin{array}{l}\text { Valor } \\
\text { mínimo }\end{array}$ & \\
\hline \multirow{4}{*}{1} & Q1 & 0,545 & 0,738 & \multirow{4}{*}{0,744} & \multirow{4}{*}{0,000} & \multirow{4}{*}{0,745} & \multirow{4}{*}{0,735} & \multirow{4}{*}{2,150} \\
\hline & Q2 & 0,536 & 0,732 & & & & & \\
\hline & Q3 & 0,573 & 0,757 & & & & & \\
\hline & Q4 & 0,496 & 0,704 & & & & & \\
\hline \multirow{3}{*}{2} & Q8 & 0,735 & 0,857 & \multirow{3}{*}{0,670} & \multirow{3}{*}{0,000} & \multirow{3}{*}{0,687} & \multirow{3}{*}{0,632} & \\
\hline & Q9 & 0,757 & 0,870 & & & & & 2,070 \\
\hline & Q10 & 0,579 & 0,761 & & & & & \\
\hline & Q12 & 0,582 & 0,763 & & & & & \\
\hline 3 & Q13 & 0,589 & 0,767 & & & & & \\
\hline 3 & Q14 & 0,625 & 0,791 & 0,768 & 0,000 & 0,771 & 0,744 & 2,458 \\
\hline & Q15 & 0,662 & 0,813 & & & & & \\
\hline & Q18 & 0,818 & 0,905 & & & & & \\
\hline 4 & Q19 & 0,837 & 0,915 & 0,702 & 0,000 & 0,720 & 0,655 & 2,343 \\
\hline & $\mathrm{Q} 20$ & 0,688 & 0,829 & & & & & \\
\hline & $\mathrm{Q} 21$ & 0,663 & 0,815 & & & & & \\
\hline & $\mathrm{Q} 22$ & 0,818 & 0,904 & & & & & \\
\hline 5 & Q23 & 0,814 & 0,902 & 0,732 & 0,000 & 0,732 & 0,722 & 2,895 \\
\hline & Q24 & 0,599 & 0,774 & & & & & \\
\hline & Q26 & 0,647 & 0,804 & & & & & \\
\hline & Q27 & 0,815 & 0,903 & & & & & \\
\hline 6 & Q28 & 0,821 & 0,906 & 0,801 & 0,000 & 0,805 & 0,775 & 2,985 \\
\hline & Q29 & 0,702 & 0,838 & & & & & \\
\hline & Q32 & 0,816 & 0,903 & & & & & \\
\hline 7 & Q34 & 0,816 & 0,903 & 0,500 & 0,000 & 0,500 & 0,500 & 1,632 \\
\hline & Q36 & 0,736 & 0,858 & & & & & \\
\hline & Q37 & 0,734 & 0,857 & & & & & \\
\hline 8 & Q38 & 0,541 & 0,736 & 0,799 & 0,000 & 0,810 & 0,748 & 3,308 \\
\hline & Q39 & 0,623 & 0,790 & & & & & \\
\hline & $\mathrm{Q} 40$ & 0,673 & 0,821 & & & & & \\
\hline & Q41 & 0,900 & 0,949 & & & & & \\
\hline 9 & Q43 & 0,914 & 0,956 & 0823 & & 0824 & & \\
\hline 9 & Q44 & 0,888 & 0,942 & 0,823 & 0,000 & 0,824 & 0,790 & 3,571 \\
\hline & Q45 & 0,869 & 0,932 & & & & & \\
\hline & Q46 & 0,616 & 0,785 & & & & & \\
\hline & Q47 & 0,707 & 0,841 & & & & & \\
\hline 10 & Q48 & 0,689 & 0,830 & 0,847 & 0,000 & 0,850 & 0,826 & 3,269 \\
\hline & Q49 & 0,518 & 0,720 & & & & & \\
\hline & Q50 & 0,739 & 0,860 & & & & & \\
\hline & Q51 & 0,569 & 0,754 & & & & & \\
\hline & Q52 & 0,665 & 0,815 & & & & & \\
\hline 11 & Q53 & 0,575 & 0,758 & 0,841 & 0,000 & 0,843 & 0,808 & 2,917 \\
\hline & Q54 & 0,508 & 0,713 & & & & & \\
\hline & Q55 & 0,601 & 0,776 & & & & & \\
\hline & Q56 & 0,538 & 0,734 & & & & & \\
\hline 12 & Q58 & 0,640 & 0,796 & 0,654 & 0,000 & 0,659 & 0,635 & 1,812 \\
\hline & Q59 & 0,633 & 0,800 & & & & & \\
\hline & Q62 & 0,565 & 0,752 & & & & & \\
\hline 13 & Q64 & 0,642 & 0,801 & 0,642 & 0,000 & 0,645 & 0,615 & 1,746 \\
\hline & Q65 & 0,539 & 0,734 & & & & & \\
\hline
\end{tabular}

Fonte: Dados da pesquisa (2014). 
das variáveis manifestas aos fatores de $1^{\text {a }}$ ordem, individualmente. Assim, testaram-se todos os 13 fatores com suas cinco variáveis manifestas, totalizando 65 variáveis observáveis e 13 latentes verificadas.

A AFE foi executada através do método dos Componentes Principais, utilizando o critério de autovalor (Eigenvalue) maior ou igual a 1 para a extração dos fatores. O método rotacional utilizado foi o Varimax.

A escolha de rotação não tem implicação nas estimativas da AFE. Tão somente conferem uma nova base vetorial (subespaço vetorial) para melhor interpretação e arranjo dos crossloadings. Importante para produzir taxonomias mais seguras sobre a direção da comunalidade de uma variável dentro do Fator. E neste caso, a utilização de uma abordagem ortogonal produz, convenientemente, uma estrutura de comunalidades disjuntas, evitando redundância analítica, facilitando a representação teórica, ainda que se admita empiricamente algum nível de associação, que fica evidente nas covariâncias dos erros de certos construtos na Análise Fatorial Confirmatória - AFC. Outro ponto relevante é que a AFE tem relevância tão somente na identificação empírica dos relacionamentos de $1^{\mathrm{a}}$ ordem e em nada conduz ou dirige a estrutura da AFC, que é o método principal da análise. Para outros critérios, observou-se o sugerido por Hair et al. (2005), são eles: Carga Fatorial $\geq 0,30$, Comunalidades $\geq 0,50, \mathrm{KMO}$ (Measure of Sampling Adequacy-MAS) $\geq 0,50$ e Bartlett Test $<0,001$.

A análise fatorial exploratória resultou na exclusão de 15 variáveis manifestas, como mostram as tabelas 8 e 9 .

A tabela 9 evidencia as variáveis manifestas que foram excluídas e o motivo para esta decisão.

Tabela 9. Variáveis manifestas excluídas após a AFE da amostra 1

\begin{tabular}{ccl}
\hline $\begin{array}{c}\text { Variável manifesta } \\
\text { excluída }\end{array}$ & Fator & Motivo \\
\hline Q5 & F1 & Baixa comunalidade \\
\hline Q6 e Q7 & F2 & Baixa comunalidade \\
\hline Q11 & F3 & Baixa comunalidade \\
\hline Q16 e Q17 & F4 & Baixa comunalidade \\
\hline Q25 & F5 & Baixa comunalidade \\
\hline Q30 & F6 & Baixa comunalidade \\
\hline Q31 & F7 & Baixa comunalidade \\
\hline Q33 e Q35 & F7 & Não suportarem pertencer ao mesmo fator que Q32 e Q34 \\
\hline Q57 e Q60 & F12 & Baixa comunalidade \\
\hline Q61 e Q63 & F13 & Baixa comunalidade
\end{tabular}

Fonte: Dados da pesquisa (2014).

Os resultados da análise fatorial exploratória foram incorporados ao modelo teórico proposto, confirmando a utilização das 13 variáveis latentes, resultando em um modelo revisado, que foi testado frente à Análise Fatorial Confirmatória.

\subsubsection{Modelagem de Equações Estruturais da Amostra de Análise}

A observação dos índices de qualidade de ajustamento da análise fatorial confirmatória seguirá os valores de referência indicados por Marôco (2010) para a tomada de decisão. Os principais indicadores de ajuste do modelo utilizados nesta pesquisa são o qui-quadrado sobre graus de liberdade (CMIN/DF), o índice de ajuste comparativo (CFI -comparative fit index), o índice de qualidade do ajustamento (GFI - goodness of it index), o índice de Tucker-Lewis (TLI) e a raiz da média dos quadrados dos erros de aproximação (RMSEA - root mean error of approximation). A tabela 10 apresenta os resultados da análise fatorial confirmatória da amostra 1 . 
Clayton L. L. de Melo - Anderson L. R. Mól - Magaly A. G. D. de Melo - Rodolfo M. R. C. Rodrigues

Tabela 10. Resultados da análise fatorial confirmatória dos 13 fatores - amostra de análise - método da máxima verossimilhança

\begin{tabular}{|c|c|c|c|c|c|c|c|c|c|c|}
\hline Fator & $\begin{array}{l}\text { Var. } \\
\text { manif. }\end{array}$ & Estimat. & $\begin{array}{l}\text { Erro } \\
\text { Padrão }\end{array}$ & CMIN/DF & GFI & CFI & TLI & RMSEA & PCLOSE & $\begin{array}{l}\text { Cov. } \\
\text { inserida* }\end{array}$ \\
\hline 1 Aversão a & Q1 & 1,000 & $\mathrm{Na}$ & \multirow{4}{*}{1,671} & \multirow{4}{*}{1,000} & \multirow{4}{*}{1,000} & \multirow{4}{*}{0,999} & \multirow{4}{*}{0,012} & \multirow{4}{*}{0,983} & \multirow{4}{*}{$\mathrm{Q} 3<\Rightarrow \mathrm{Q} 4$} \\
\hline riscos para & Q2 & $1,152 * * *$ & 0,042 & & & & & & & \\
\hline ganhos de alta & Q3 & $0,943 * * *$ & 0,037 & & & & & & & \\
\hline probabilidade & Q4 & $0,763 * * *$ & 0,033 & & & & & & & \\
\hline \multirow{3}{*}{$\begin{array}{l}2 \text { Propensão a } \\
\text { riscos para perdas } \\
\text { de alta } \\
\text { probabilidade }\end{array}$} & Q8 & 1,000 & $\mathrm{Na}$ & \multirow{3}{*}{0,093} & \multirow{3}{*}{1,000} & \multirow{3}{*}{1,000} & \multirow{3}{*}{1,000} & \multirow{3}{*}{0,000} & \multirow{3}{*}{0,999} & \\
\hline & Q9 & $1,048 * * *$ & 0,019 & & & & & & & \\
\hline & Q10 & $0,695 * * *$ & 0,017 & & & & & & & \\
\hline \multirow{4}{*}{$\begin{array}{l}3 \text { Propensão a } \\
\text { riscos para } \\
\text { ganhos de baixa } \\
\text { probabilidade }\end{array}$} & Q12 & 1,000 & $\mathrm{Na}$ & \multirow{4}{*}{4,634} & \multirow{4}{*}{1,000} & \multirow{4}{*}{0,999} & \multirow{4}{*}{0,996} & \multirow{4}{*}{0,028} & & \\
\hline & Q13 & $1,037 * * *$ & 0,03 & & & & & & 0.896 & Q14 \\
\hline & Q14 & $0,828 * * *$ & 0,027 & & & & & & 0,090 & Q15 \\
\hline & Q15 & $0,867 * * *$ & 0,026 & & & & & & & \\
\hline 4 Aversão a & Q18 & $1,352 * * *$ & 0,018 & & & & & & & \\
\hline riscos para perdas & Q19 & $1,353 * * *$ & 0,018 & 1,080 & 1,000 & 1,000 & 1,000 & 0,004 & 0,991 & \\
\hline probabilidade & Q20 & 1,000 & $\mathrm{Na}$ & & & & & & & \\
\hline 5 Aversão a & Q21 & $1,645 * * *$ & 0,025 & & & & & & & \\
\hline riscos para & Q22 & $1,893 * * *$ & 0,022 & & & & & & & Q22 $\quad$ => \\
\hline ganhos $\quad$ em & Q23 & $1,411 * * *$ & 0,019 & 1,100 & 1,000 & 1,000 & 1,000 & 0,005 & 0,991 & Q24 Q23 \\
\hline $\begin{array}{l}\text { melhor } \\
\end{array}$ & Q24 & 1,000 & $\mathrm{Na}$ & & & & & & & \\
\hline 6 Propensão a & Q26 & 1,000 & $\mathrm{Na}$ & & & & & & & \\
\hline riscos para perdas & Q27 & $1,228 * * *$ & 0,016 & 3008 & 1000 & 1000 & 0999 & 0021 & 0953 & $\begin{array}{ll}\text { Q26 } & <=> \\
027 & 026\end{array}$ \\
\hline em mudanças & Q28 & $1,411 * * *$ & 0,017 & J,000 & 1,000 & 1,000 & 0,999 & $0,0<1$ & 0,9נ5 & $\Leftrightarrow 029$ \\
\hline para pior & Q29 & $1,257 * * *$ & 0,019 & & & & & & & \\
\hline 8 Prazer por & Q36 & 1,000 & $\mathrm{Na}$ & & & & & & & Q36 $\quad \Leftrightarrow$ \\
\hline ganhar maior que & Q37 & $1,020 * * *$ & 0,015 & & & & & & & Q38 Q38 \\
\hline a dor por perder - & Q38 & $0,638 * * *$ & 0,015 & 1,903 & 1,000 & 1,000 & 0,999 & 0,014 & 0,999 & $\Leftrightarrow \quad$ Q39 \\
\hline Pequenas & Q39 & $0,676 * * *$ & 0,015 & & & & & & & $\begin{array}{ll}\text { Q38 } & <=> \\
\text { Q40 } & \text { O39 }\end{array}$ \\
\hline quantias & Q40 & $0,697 * * *$ & 0,015 & & & & & & & $\Leftrightarrow=>Q 40$ \\
\hline 9 Prazer por & Q41 & $1,179 * * *$ & 0,01 & & & & & & & \\
\hline ganhar se & Q43 & $1,183 * * *$ & 0,009 & & & & & & & Q43 $\quad \Leftrightarrow$ \\
\hline aproxima da dor & Q44 & $1,051 * * *$ & 0,009 & 0,129 & 1,000 & 1,000 & 1,000 & 0,000 & 0,999 & $\begin{array}{l}\text { Q45 Q44 } \\
\Leftrightarrow-\rightarrow 45\end{array}$ \\
\hline quantias & Q45 & 1,000 & $\mathrm{Na}$ & & & & & & & \\
\hline & Q46 & 1,000 & $\mathrm{Na}$ & & & & & & & Q46 $\quad \Leftrightarrow$ \\
\hline 10 Efeito & Q47 & $1,135 * * *$ & 0,024 & & & & & & & Q47 Q46 \\
\hline disposição para & Q48 & $1,154 * * *$ & 0,028 & 3,764 & 1,000 & 1,000 & 0,997 & 0,024 & 0,929 & $\Leftrightarrow \quad$ Q49 \\
\hline ganhos & Q49 & $0,926 * * *$ & 0,024 & & & & & & & $\begin{array}{ll}\text { Q47 } & <=> \\
\mathrm{O} 48 & \mathrm{O} 48\end{array}$ \\
\hline & Q50 & $1,306 * * *$ & 0,03 & & & & & & & $<=>49$ \\
\hline & Q51 & 1,000 & $\mathrm{Na}$ & & & & & & & Q51 \\
\hline $11 \quad$ Efeito & Q52 & $1,294 * * *$ & 0,033 & & & & & & & Q52 \\
\hline disposição para & Q53 & $1,364 * * *$ & 0,043 & 2,649 & 1,000 & 1,000 & 0,998 & 0,019 & 0,996 & $<=>$ \\
\hline perdas & Q54 & $1,179 * * *$ & 0,041 & & & & & & & Q54 \\
\hline & Q55 & $1,237 * * *$ & 0,038 & & & & & & & Q55 \\
\hline & Q56 & 1,000 & $\mathrm{Na}$ & & & & & & & \\
\hline $\begin{array}{l}12 \text { Apego a bens } \\
\text { materiais }\end{array}$ & Q58 & $1,183 * * *$ & 0,031 & 0,000 & 1,000 & 1,000 & 1,000 & 0,000 & 1,000 & \\
\hline & Q59 & $1,097 * * *$ & 0,029 & & & & & & & \\
\hline 13 Acumulação & Q62 & 1,000 & $\mathrm{Na}$ & & & & & & & \\
\hline da aversão à & Q64 & $1,163 * * *$ & 0,032 & 0,010 & 1,000 & 1,000 & 1,000 & 0,000 & 1,000 & \\
\hline de posse do ativo & Q65 & $1,000 * * *$ & 0,033 & & & & & & & \\
\hline
\end{tabular}

na: não se aplica

* covariâncias inseridas com base nos índices de modificação sugeridos pelo software Amos

***significante a 0,001

Fonte: Dados da pesquisa (2014). 
A tabela 10 mostra que a AFC da amostra de análise confirmou a utilização dos fatores resultantes da AFE. Todos os índices de qualidade de ajustamento se encontram em padrões aceitáveis. Apenas o fator 7 não pôde ser extraído, por permanecer com apenas duas variáveis manifestas, gerando um sistema subidentificado. Dessa forma, o fator 7 será observado frente à $\mathrm{AFC}$ apenas quando o modelo completo for executado. A análise também utilizou o método da distribuição assintótica livre na AFC, obtendo índices semelhantes aos do método da máxima verossimilhança.

Os resultados da análise fatorial confirmatória foram incorporados ao modelo teórico proposto, resultando no modelo de aversão à perda apresentado na figura 2 .

Figura 2. Modelo de aversão à perda reespecificado para a amostra de análise

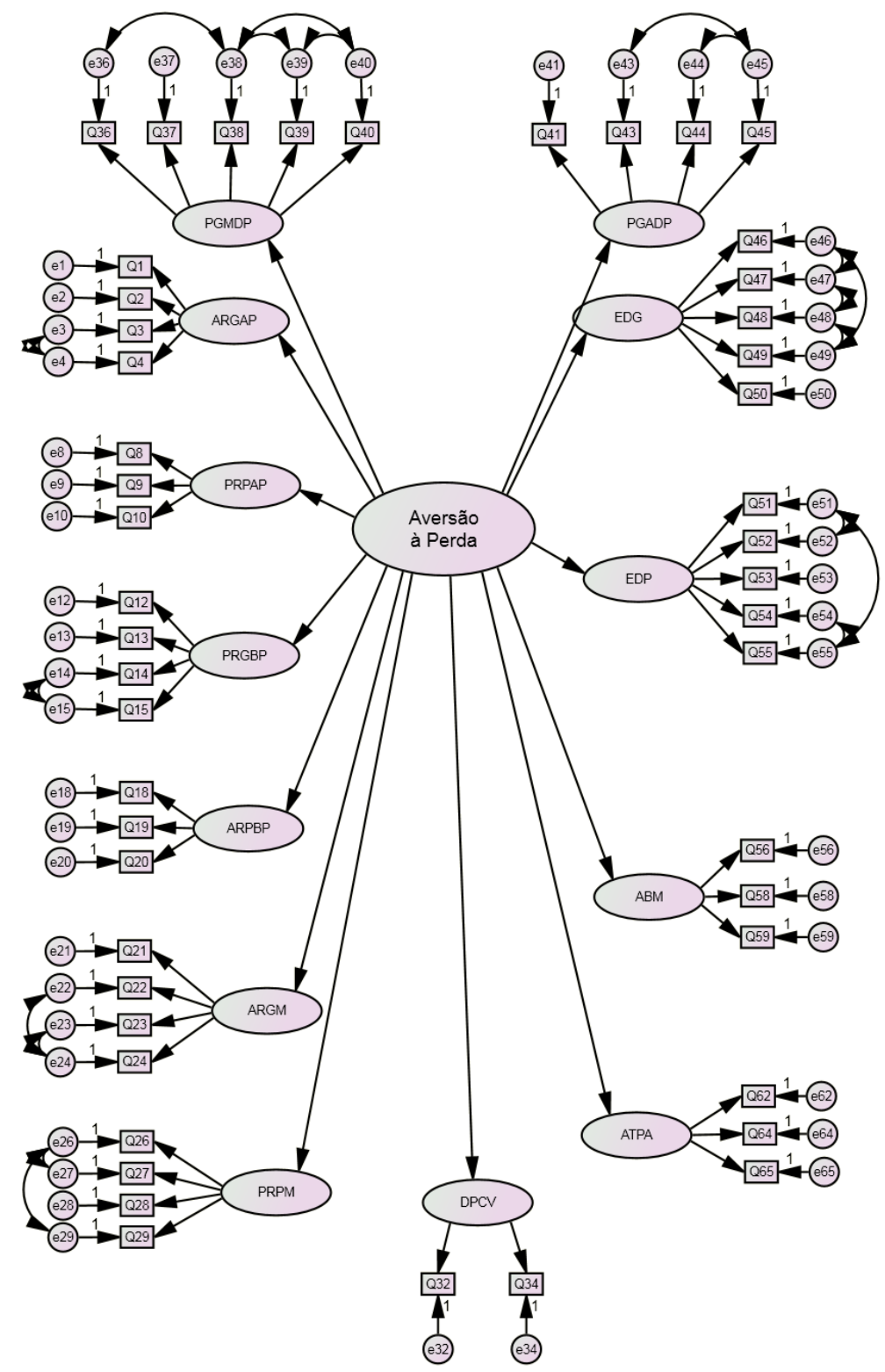

ARGAP = aversão a riscos para ganhos de alta probabilidade; PRPAP = propensão a riscos para perdas de alta probabilidade; $\mathrm{PRGBP}=$ propensão a riscos para ganhos de baixa probabilidade; $\mathrm{ARPBP}=$ aversão a riscos para perdas de baixa probabilidade; ARGM = aversão a riscos para ganhos em mudanças para melhor; PRPM = propensão a riscos para perdas em mudanças para pior; DPCV = divergência entre preços de compra e de venda; PGMDP = prazer por ganhar maior que a dor por perder - pequenas quantias; PGADP = prazer por ganhar se aproxima da dor por perder - altas quantias; EDG = efeito disposição para ganhos; EDP = efeito disposição para perdas; $\mathrm{ABM}$ = apego a bens materiais; ATPA = acumulação da aversão à perda por tempo de posse do ativo Fonte: Dados da pesquisa (2014). 
Tabela 11. Resultados da análise fatorial confirmatória do modelo empírico de aversão à perda - amostra de Análise - método da máxima verossimilhança

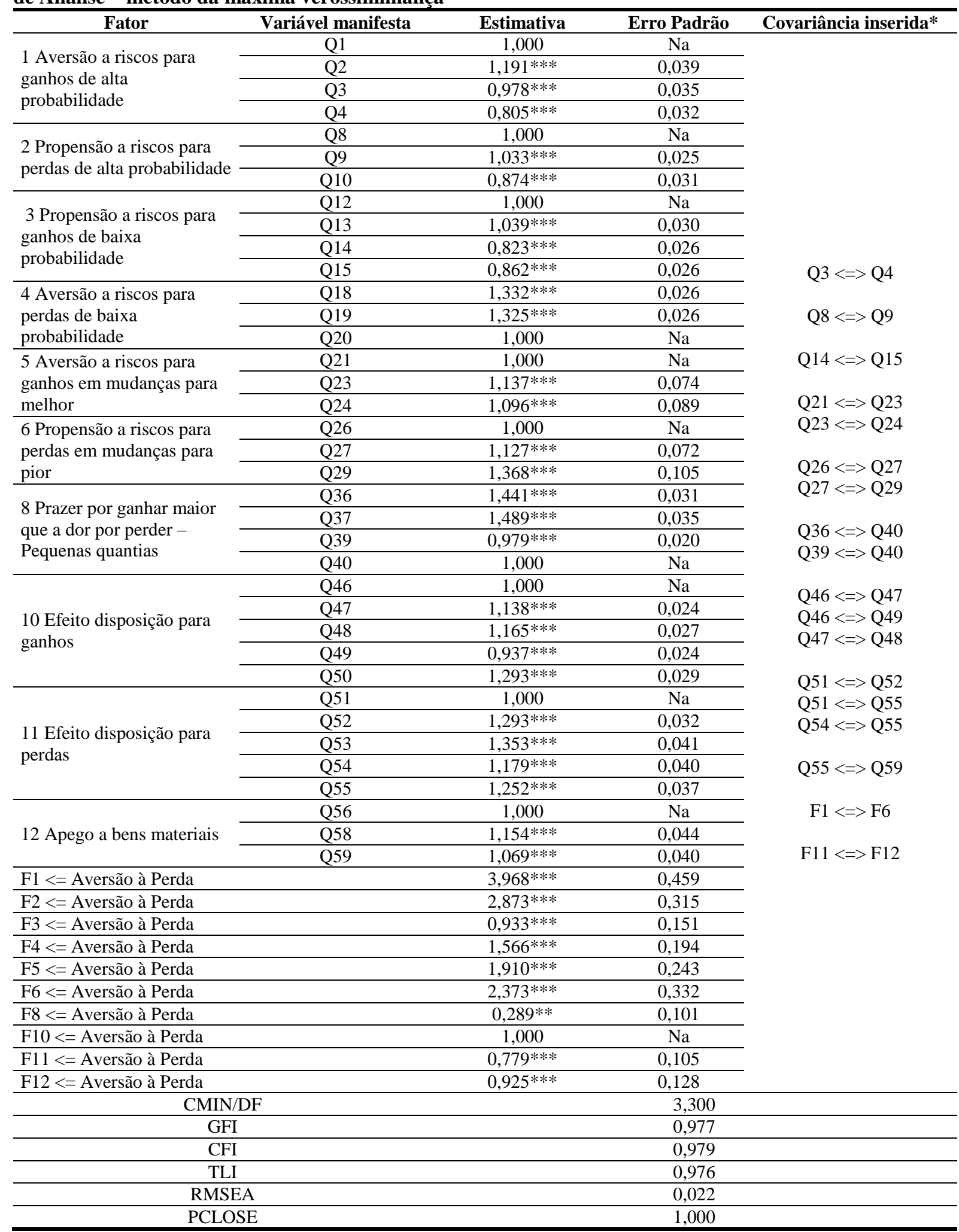

na: não se aplica

* covariâncias inseridas ou mantidas com base nos índices de modificação sugeridos pelo software Amos

** significante a 0,01

$* * *$ significante a 0,001

Fonte: Dados da pesquisa (2014). 
Os resultados da análise fatorial exploratória e confirmatória na amostra de análise foram testados frente à amostra de validação, com intuito de verificar a estabilidade dos resultados. A análise da amostra de validação confirmou os resultados obtidos na amostra de análise, não havendo necessidade de exclusões de variáveis ou alterações no modelo formativo da AFC da figura 2.

\subsection{Modelo Empírico de Aversão à Perda}

Este tópico apresenta a execução do modelo formativo resultante da análise fatorial exploratória e confirmatória apresentado na figura 2, frente às amostras de análise e validação. Assim, serão utilizados neste tópico os resultados da modelagem de equações estruturais e análise fatorial confirmatória do modelo empírico de aversão à perda da amostra de análise.

Ao se executar o modelo estrutural da figura 2 de forma completa, com todos os fatores e variáveis observáveis simultaneamente, observou-se a necessidade de reespecificação.

Como forma de obter um melhor ajustamento do modelo, foram excluídos três fatores: o fator 7 - Divergência entre preços de compra e de venda (DPCV), que não havia sido extraído na AFE; o fator 9 - Prazer por ganhar se aproxima da dor por perder - altas quantias (PGADP); e, o fator 13 - Acumulação da aversão à perda por tempo de posse do ativo (ATPA).

As 10 variáveis latentes utilizadas no modelo empírico de aversão à perda da (figura 3) foram analisadas na análise fatorial confirmatória de forma conjunta, observando-se os passos descritos no tópico anterior para a verificação dos resultados. A tabela 11 apresenta os resultados da AFC para os dez fatores do modelo, obtidos através do método da máxima verossimilhança.

A AFC do modelo empírico de aversão à perda da amostra de análise confirmou a utilização dos dez fatores utilizados. Todos os índices de qualidade de ajustamento se encontram em padrões aceitáveis. O CMIN/DF, apesar de sofrível, é aceitável, e todos os demais índices de ajustamento obtiveram escores considerados bons. Além disso, todas as variáveis observáveis e latentes foram significantes a $1 \%$, como mostra a tabela 6 . A análise também utilizou o método da distribuição assintótica livre na AFC, obtendo índices semelhantes aos do método da máxima verossimilhança. O modelo é considerado superidentificado.

A figura 3 apresenta o modelo empírico reespecificado de aversão à perda.

\subsubsection{Teste do Modelo Empírico nas Amostras de Análise e Validação}

O modelo empírico de aversão à perda, da figura 3, foi testado frente às amostras de análise e validação, pelos métodos da máxima verossimilhança e distribuição assintótica livre (ADF), com o intuito de testar sua estabilidade e adequação. O modelo empírico de aversão à perda se mostrou adequado e estável, obtendo níveis aceitáveis em seus índices de qualidade de ajustamento pelos dois métodos utilizados: máxima verossimilhança e distribuição assintótica livre.

\subsubsection{Análise das Hipóteses Relacionadas ao Objetivo Principal de Pesquisa}

As hipóteses de pesquisa relacionadas ao objetivo principal, apresentadas no tópico 2 , podem agora ser analisadas, já que a análise fatorial confirmatória de $2^{\mathrm{a}}$ ordem gerou um modelo empírico de aversão à perda que possibilita verificar as relações válidas entre os fatores de $1^{a}$ ordem e a composição da variável latente aversão à perda ( $2^{\mathrm{a}}$ ordem). Dessa forma, conforme o modelo empírico de aversão à perda da figura 3 , a análise das hipóteses é descrita na tabela 12 . 
Figura 3. Modelo empírico de aversão à perda

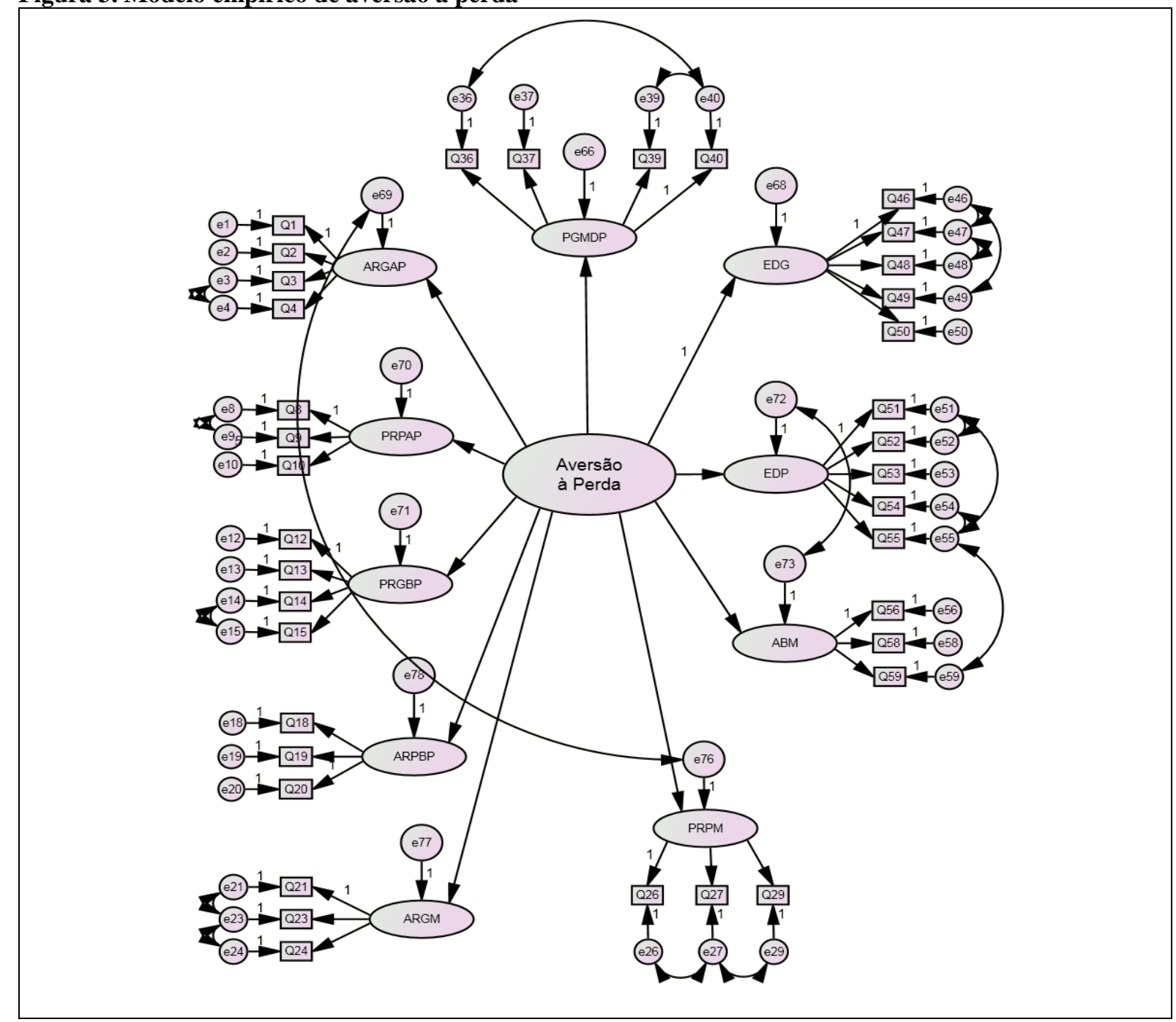

ARGAP $=$ aversão a riscos para ganhos de alta probabilidade; PRPAP $=$ propensão a riscos para perdas de alta probabilidade; $\mathrm{PRGBP}=$ propensão a riscos para ganhos de baixa probabilidade; $\mathrm{ARPBP}=$ aversão a riscos para perdas de baixa probabilidade; ARGM = aversão a riscos para ganhos em mudanças para melhor; $\mathrm{PRPM}=$ propensão a riscos para perdas em mudanças para pior; PGMDP = prazer por ganhar maior que a dor por perder - pequenas quantias; $\mathrm{EDG}=$ efeito disposição para ganhos; $\mathrm{EDP}=$ efeito disposição para perdas; $\mathrm{ABM}=$ apego a bens materiais.

Fonte: Dados da pesquisa (2014).

Para se conseguir a estabilidade do modelo empírico de aversão à perda foi necessário excluir três fatores: o 7 - Divergência entre preços de compra e de venda (DPCV), o 9 - Prazer por ganhar se aproxima da dor por perder - altas quantias (PGADP) e o fator 13 - Acumulação da aversão à perda por tempo de posse do ativo (ATPA).

Estes três fatores, apesar de se mostrarem viáveis durante a execução da AFE, não se mostraram adequados quando da execução da AFC. O fator 7 - Divergência entre preços de compra e de venda (DPCV) corresponde ao fenômeno conhecido na literatura internacional como endowment effect, descoberto por Thaler (1980) e trabalhado pelo próprio Daniel Kahneman em 1990. Dessa forma, por se tratar de um fenômeno bem documentado internacionalmente, é possível que sua exclusão nesta pesquisa tenha por origem a não adequação das variáveis manifestas deste estudo, de forma a captar o fenômeno em questão. $\mathrm{O}$ mesmo não se pode afirmar em relação à exclusão dos fatores 9 - Prazer por ganhar se aproxima da dor por perder - altas quantias (PGADP) e fator 13 - Acumulação da aversão à perda por tempo de posse do ativo (ATPA), por serem menos robustos em testes realizados na literatura 
internacional. Assim, a exclusão destes dois fatores pode significar que, apesar de existirem, já que foram timidamente confirmados na literatura, não suportam integrar um modelo de medida que representem a aversão à perda.

Tabela 12. Análises das hipóteses principais de pesquisa

\begin{tabular}{|c|c|}
\hline Hipótese de pesquisa & Decisão \\
\hline $\begin{array}{l}\text { Hipótese } 1\left(\mathrm{H}_{1}\right) \text { : Aversão a riscos para ganhos de alta probabilidade influencia positivamente o } \\
\text { nível de aversão à perda }\end{array}$ & Não rejeição \\
\hline $\begin{array}{l}\text { Hipótese } 2\left(\mathrm{H}_{2}\right) \text { : Propensão a riscos para perdas de alta probabilidade influencia positivamente } \\
\text { o nível de aversão à perda. }\end{array}$ & Não rejeição \\
\hline $\begin{array}{l}\text { Hipótese } 3\left(\mathrm{H}_{3}\right) \text { : Propensão a riscos para ganhos de baixa probabilidade influencia } \\
\text { positivamente o nível de aversão à perda }\end{array}$ & Não rejeição \\
\hline $\begin{array}{l}\text { Hipótese } 4\left(\mathrm{H}_{4}\right) \text { : Aversão a riscos para perdas de baixa probabilidade influencia positivamente } \\
\text { o nível de aversão à perda. }\end{array}$ & Não rejeição \\
\hline $\begin{array}{l}\text { Hipótese } 5\left(\mathrm{H}_{5}\right) \text { : Aversão a riscos para ganhos em mudanças influencia positivamente o nível } \\
\text { de aversão à perda }\end{array}$ & Não rejeição \\
\hline $\begin{array}{l}\text { Hipótese } 6\left(\mathrm{H}_{6}\right) \text { : Propensão a riscos para perdas em mudanças influencia positivamente o nível } \\
\text { de aversão à perda. }\end{array}$ & Não rejeição \\
\hline $\begin{array}{l}\text { Hipótese } 7\left(\mathrm{H}_{7}\right) \text { : Diferença entre preços de venda e de compra influencia positivamente o nível } \\
\text { de aversão à perda. }\end{array}$ & Rejeição \\
\hline $\begin{array}{l}\text { Hipótese } 8\left(\mathrm{H}_{8}\right) \text { : Tradeoff do prazer de ganhar e a dor por perder pequenas quantias influencia } \\
\text { positivamente o nível de aversão à perda. }\end{array}$ & Não rejeição \\
\hline $\begin{array}{l}\text { Hipótese } 9\left(\mathrm{H}_{9}\right) \text { : Tradeoff do prazer de ganhar e dor por perder altas quantias influencia } \\
\text { positivamente o nível de aversão à perda. }\end{array}$ & Rejeição \\
\hline $\begin{array}{l}\text { Hipótese } 10\left(\mathrm{H}_{10}\right) \text { : Efeito Disposição para Ganhos influencia positivamente o nível de aversão } \\
\text { à perda. }\end{array}$ & Não rejeição \\
\hline $\begin{array}{l}\text { Hipótese } 11\left(\mathrm{H}_{11}\right) \text { : Efeito Disposição para Perdas influencia positivamente o nível de aversão à } \\
\text { perda. }\end{array}$ & Não rejeição \\
\hline Hipótese $12\left(\mathrm{H}_{12}\right)$ : Apego a Bens Materiais influencia positivamente o nível de aversão à perda. & Não rejeição \\
\hline $\begin{array}{l}\text { Hipótese } 13\left(\mathrm{H}_{13}\right) \text { : Acumulação pelo tempo de posse influencia positivamente o nível de } \\
\text { aversão à perda. }\end{array}$ & Rejeição \\
\hline
\end{tabular}

Fonte: elaboração própria.

É importante, ainda, evidenciar que o modelo empírico de aversão à perda foi desenvolvido em uma pesquisa de abrangência nacional e, portanto, os resultados apontados podem, de alguma forma, ter influencia de variáveis culturais, sociais e demográficas, dentre outras. Assim, é impossível prever como o modelo formativo de aversão à perda se comportaria em outro país e se as variáveis latentes 7 - Divergência entre preços de compra e de venda (DPCV), o 9 - Prazer por ganhar se aproxima da dor por perder - altas quantias (PGADP) e o fator 13 - Acumulação da aversão à perda por tempo de posse do ativo (ATPA).

\section{CONSIDERAÇÕES FINAIS}

Este estudo teve por objetivo principal propor um modelo estrutural por meio da modelagem de equações estruturais que representasse os determinantes da aversão à perda em decisões financeiras. Para se atingir o objetivo principal, inicialmente, foi realizado um levantamento bibliográfico nacional e internacional com o objetivo de criar um modelo estrutural que representasse adequadamente a aversão à perda. O modelo estrutural criado a partir do embasamento teórico possuía 13 variáveis latentes e 65 variáveis observáveis (figura 1). A partir da criação do modelo estrutural, um questionário contendo as 65 variáveis 
observáveis, mais as seis questões relacionadas aos objetivos específicos, foi abrigado em um sitio na internet, como forma de viabilizar a coleta de dados.

A amostra utilizada neste estudo foi composta por estudantes de graduação e profissionais de todas as áreas de conhecimento do CNPq. Para viabilizar a coleta de dados, o pesquisador entrou em contado com as pró-reitorias de graduação de pelo menos três universidades federais por região do país, mais o Distrito Federal, totalizando 21 universidades federais contatadas, e com os sindicatos, conselhos de classe e associações nacionais, com o intuito de que essas instituições enviassem uma breve apresentação com o link que conduzia ao questionário de pesquisa para seus estudantes e profissionais cadastrados. Cinco universidades federais enviaram a mensagem diretamente para os seus alunos, UFRN, UFBA, UFG, UnB e UFMG, e outras quatro, UFPA, UNIFAP, UFAC e UFPB, por limitações de sistema, enviaram para as coordenações de cursos de graduação para que estas a repassassem aos alunos.

Já em relação aos sindicatos de classe, conselhos e associações, houve recusa de envio da mensagem pela maioria das instituições, o que conduziu o pesquisador a outras estratégias de divulgação em relação aos profissionais. Foram coletadas 9.553 observações válidas. Entretanto, após o tratamento de outliers, a amostra permaneceu com 9.308 observações. Por meio do boxplot identificou-se 245 observações extremas (outliers) que foram excluídas da análise. Como forma de compensar o fato de a amostra utilizada ser não probabilística, foi utilizada a técnica de validação cruzada, sendo o banco de dados dividido aleatoriamente em duas amostras, cada uma com 4.654 observações.

Para a análise do objetivo principal de pesquisa foram estabelecidas 13 hipóteses de pesquisa, cada uma representando a relação de um dos 13 fatores com a aversão à perda. Para essa análise foram utilizadas as técnicas estatísticas denominadas análise fatorial exploratória e análise fatorial confirmatória, executadas através dos softwares IBM® SPSS® Statistics 19.0 e IBM® SPSS $®$ Amos 18.0.

As hipóteses de pesquisa relacionadas ao objetivo principal foram analisadas e os resultados apontaram para a rejeição de três delas: a hipótese 7 , que tratava da relação entre o Fator 7 - Diferença entre preços de compra e de venda e a aversão à perda; a hipótese 9, que estabelecia a relação entre o Fator 9 -Tradeoff do prazer de ganhar e dor por perder altas quantias e a aversão à perda; e, a hipótese 13, que previa a relação entre a variável latente 13 Acumulação pelo tempo de posse do ativo e a aversão à perda. As outras dez hipóteses, que previam a relação entre a aversão à perda e os fatores 1 - Aversão a riscos para ganhos de alta probabilidade, 2 - Propensão a riscos para perdas de alta probabilidade, 3 - Propensão a riscos para ganhos de baixa probabilidade, 4 - Aversão a riscos para perdas de baixa probabilidade, 5 - Aversão a riscos para ganhos em mudanças, 6 - Propensão a riscos para perdas em mudanças, 8 - Tradeoff do prazer de ganhar e a dor por perder pequenas quantias, 10 - Efeito disposição para ganhos, 11 - Efeito disposição para perdas e 12 - Apego a bens materiais, não foram rejeitadas, resultando em um modelo empírico de aversão à perda descrito na figura 3.

Deve-se salientar, entretanto, que todos os 13 fatores constantes no modelo teórico proposto da figura 1 foram considerados significantes pela análise fatorial exploratória e análise fatorial confirmatória, nas amostras de análise e validação.

O modelo empírico de aversão à perda resultante da análise dos dados, com dez fatores remanescentes, foi, então, testado frente às amostras de análise e validação, como forma de verificar sua estabilidade e invariância. Os testes mostraram que o modelo empírico é adequado e estável, apresentando bons índices de qualidade de ajustamento e se mostrando invariante nas duas amostras. É importante destacar a inexistência na literatura internacional de um modelo que represente a aversão à perda por meio da Análise Fatorial Confirmatória de $2^{\mathrm{a}}$ ordem. Os estudos anteriores que investigaram a aversão à perda observaram os fatores descritos individualmente, ou seja, este é o primeiro estudo que observa o comportamento dos fatores simultaneamente. Assim, não foi possível realizar comparações. 
Como sugestão para futuras pesquisas, o modelo empírico de aversão à perda resultante deste trabalho pode ser aplicado a outras amostras não contempladas neste estudo, como forma de verificar sua autenticidade.

\section{REFERÊNCIAS}

ABDELLAOUI, M.; BLEICHRODT, H.; PARASCHIV, C. Loss Aversion Under Prospect Theory: A Parameter-Free Measurement. Management Science, v. 53, n. 10, p. 1659-1674, out. 2007.

ABELER, J.; FALK, A.; GOETTE, L.; HUFFMAN, D. Reference points and effort provision. The American Economic Review, v. 101, n. 2, p. 470-492, 2011.

ANDRADE, L. K. P. Um estudo sobre a influência das ilusões cognitivas em processos de tomada de decisão de investimentos sob a ótica da teoria das perspectivas (Prospect Theory) de Kahneman e Tversky. 2012. 126f. Dissertação (Mestrado Profissionalizante em Administração) - Faculdades Ibmec, 2012.

BASSO, L. F. C.; KIMURA, H.; KRAUTER, E. Paradoxos em finanças: teoria moderna versus finanças comportamentais. Revista de Administração de Empresas - RAE. v. 46. n. 1, p. 41-58, 2006.

BARBERIS, N.; THALER, R. A survey of behavioral finance. Bureau of Economic Research Working Paper, Set. 2003. In: Advances in Behavioral Finance, v. 2. Princeton University Press. Russell Sage Foundation, 2005.

BARBERIS, N. C.Thirty years of prospect theory in economics: A review and assessment. National Bureau of Economic Research, 2012.

BLAVATSKYY, P. R.; POGREBNA, G. Loss Aversion? Not with Half a Million on the Table!. IEW - Working Papers, n. iewwp274, Institute for Empirical Research in Economics University of Zurich, 2007.

CNPQ, Conselho Nacional de Desenvolvimento Científico e Tecnológico. Tabela das áreas do conhecimento. Disponível em: <http://www.capes.gov.br/avaliacao/tabela-de-areas-deconhecimento>. Acesso em 10 fev. 2014.

CARIFIO, J.; PERLA, R. Ten common misunderstandings, misconceptions, persistent myths and urban legends about Likert scales and Likert response formats and their antidotes.

Journal of Social Sciences, v. 2, p. 106-116, 2007.

CARMON, Ziv; ARIELY, Dan. Focusing on the Forgone: How Value CanAppear So

Different to Buyers and Sellers.Journal of Consumer Research, v. 27, p. 360-70, dez, 2000.

CORRAR, L. J.; PAULO, E.; DIAS FILHO, J. M.. Análise Multivariada. 1. ed. São Paulo: Atlas, 2011.

CURRAN, P. J.; WEST, S. G.; FINCH, J. F. The robustness of test statistics to nonnormality and specification error in confirmatory factor analysis. Psychological methods, v. 1, n. 1, p. 16, 1996. 
DA COSTA, N. et al. The disposition effect and investor experience. Journal of Banking and Finance, v. 37, n. 5, p. 1669-1675, 2013.

EIICHI, T. et al.Endowment Effect and Trade Policy Preferences: Evidence from a survey on individuals. RIETI Discussion Paper Series, v. 13-E-009, 2013.

EREV, I.; ERT, E.; YECHIAM, E. Loss Aversion, Diminishing Sensitivity, and the Effect of Experience on Repeated Decisions. Journal of Behavioral Decision Making, v. 21, p. 575597, 2008.

FINNEY, S. J.; DISTEFANO, C. Non-normal and categorical data in structural equation modeling. Structural equation modeling: A second course, v. 10, n. 6, p. 269-314, 2006.

GACHTER, S.; JOHNSON, E. J.; HERRMANN, A. Individual Level Loss Aversion in Riskless and Risky Choices. CeDEx Discussion Paper Series, n. 3293, nov. 2010.

GALIN, A. Endowment Effect in negotiations: group versus individual decision-making. Theory and decision, v. 75, n. 3, p. 389-401, 2013.

GLASS, G. V.; PECKHAM, P. D.; SANDERS, J. R. Consequences of failure to meet assumptions underlying the analyses of variance and covariance. Review of Educational Research, v. 42, n. 3, p. 237-288, 1972.

GOLLIER, C. What Does Classical Theory Have to Say about Household Portfolios? Ed. of the Universite de Toulouse, and Institut Universitaire de France, October, 2000.

GRABLE, J.E.; LYTTON, R.H. Assessing financial risk tolerance: do demographic, socioeconomic and attitudinal factors work?. Family Relations and Human Development/Family Economics and Resource Management Biennial, p. 80-88, 1999.

KLINE, R. B. et al. Beyond significance testing: Reforming data analysis methods in behavioral research. 2004.

LEONE, R. J. G.; GUIMARÃES, T. C. O Comportamento Financeiro Durante e Após a Crise Financeira de 2008 Sob a Ótica da Teoria dos Prospectos. Revista de Contabilidade do Mestrado em Ciências Contábeis da UERJ, v. 17, n. 3, p. 119-140, 2013.

HARINCK, F.; VAN DIJK, E.; VAN BEEST, I.; MERSMANN, P. When gains loom larger than losses. Reversed loss aversion for small amounts of money. Psychological Science, 18, 1099-1105, 2007.

HAIR JR., J.F.; ANDERSON, R.E.; TATHAM, R.; BLACK, W. Análise Multivariada de Dados. 5 ed. New Jersey: Prentice Hall, 2005.

HOCHMAN, G.; YECHIAM, E. Loss Aversion in the Eye and in the Heart: The Autonomic Nervous System's Responses to Losses. Journal of Behavioral Decision Making, v. 24, p. 140-156, 2011.

HOCHMAN, G.; YECHIAM, E. Prospect theory: an analysis of decision under risk. Econometrica, v.47, n. 2, p. 263-291, mar. 1979. 
DETERMINANTES DA AVERSÃO À PERDA EM DECISÕES FINANCEIRAS: UMA INVESTIGAÇÃO POR MEIO DE MODELOS FATORIAIS

HOCHMAN, G.; YECHIAM, E. Choices, values, and frames. American Psychologist, v.39, n. 4, p. 341-350, abr. 1984.

HOCHMAN, G.; YECHIAM, E. The Endowment Effect, Loss Aversion, and Status Quo Bias. The Journal of Economic Perspectives, v. 5, n. 1, p. 193-206, 1991

HOCHMAN, G.; YECHIAM, E. Choices, Values, and Frames. Princenton University Press, New York, 1997.

KAHNEMAN, D.; KNETSCH, J. L.; THALER, R. H. Experimental Tests of the Endowment Effect and the Coase Theorem. The Journal of Political Economy, v. 98, n. 6, p. 1325-1348, dez, 1990.

KAHNEMAN, Dl. A psychological perspective on economics. The american economic review, v. 93, n. 2, p. 162-168, 2003.

KARLE, H.; KIRCHSTEIGER, G.; PEITZ, Martin. Loss Aversion and Consumption Choice: Theory and Experimental Evidence. Economics Letters, v. 123, p. 33-36, 2013.

KNETSCH, J. L. The Endowment Effect and Evidence of Nonreversible Indifference Curves. The American Economic Review, v. 79, n. 5, p. 1277-1284, dez 1989.

KOGUT, T.; KOGUT, E. Possession attachment: Individual differences in the endowment effect. Journal of Behavioral Decision Making, v. 24, n.4, p. 377-393, 2011.

LEVIN, I. P.; SCHREIBER, J.; LAURIOLA, M.; GAETH G. J. A Tale of Two Pizzas: Building Up from a Basic Product Versus Scaling Down from a Fully-Loaded Product. Marketing Letters, v. 13, p. 335-344, 2002.

LIU, Y.; FAN, Z.; ZHANG, Y. Risk decision analysis in emergency response: a method based on cumulative prospect theory. Computers \& Operations Research, v. 42, p. 75-82, 2014.

MADDUX, W. W.; YANG, H.; FALK, C.; ADAM, H.; ADAIR, W.; ENDO, Y.; HEINE, S. $\mathrm{J}$. For whom is parting with possessions more painful? Cultural differences in the endowment effect. Psychological Science, v. 21, n. 12, p. 1910-1917, 2010.

MALHOTRA, N. K. Pesquisa de marketing: uma orientação. 4. ed. São Paulo: Bookman, 2004.

MATIAS-PEREIRA, J.. Manual de metodologia da pesquisa cientifica. 2. ed. São Paulo: Atlas, 2010.

MARÔCO, J. Análise de Equações Estruturais: fundamentos teóricos, softwares \& aplicações. Pêro Pinheiro: ReportNumber, 2010.

MARÔCO, J.; MARQUES, T. G. Qual a fiabilidade do alfa de Cronbach? Questões antigas e soluções modernas? Laboratório de Psicologia, v. 4, n. 1, p. 65-90, 2006. 
MELO, C. L. L.; SILVA, C. A. T. Finanças comportamentais: um estudo da influência da faixa etária, gênero e ocupação na aversão à perda. Revista de Contabilidade e

Organizações/RCO - FEA-RP/USP, v. 4, n. 8, p. 3-23, jan/abr. 2010.

NASH, J. G.; ROSENTHAL, R. A. An Investigation of the Endowment Effect in the Context of a College Housing Lottery. Journal of Economic Psychology, 2014.

NOVEMSKY, N.; KAHNEMAN, D. How Do Intentions Affect Loss Aversion? Journal of Marketing Research, v. 42, p. 139-140, maio 2005.

ODEAN, T. Are Investors Reluctant to Realize Their Losses? The Journal of Finance, v. 53, n. 5, p. 1775-1798, out, 1998.

OKADA, E. Trade-Ins, Mental Accounting, and Product Replacement Decisions. Journal of Consumer Research, v. 27, p. 433-46, mar. 2001.

PASQUARIELLO, P. Prospect Theory and market quality. Journal of Economic Theory, v. 149, p. 276-310, 2014.

PETERS, E.; SLOVIC, P.; GREGORY, R. The Role of affect in the WTA/WTP disparity. Journal of Behavioral Decision Making. v. 16, p. 309-330, 2003.

PUTLER, D. Incorporating Reference Price Effects into a Theory of Consumer Choice.Marketing Science, v. 11, p. 287-309, 1992.

RAU, H. A. The disposition effect and loss aversion: Do gender differences matter? Economics Letters, v. 123, p. 33-36, 2014.

SCHAPIRE, R. E.; SINGER, Y. BoosTexter: A Boosting-based System for Text Categorization. Machine Learning, v. 39, n. 2, p. 135-168, 2000.

SCHIFFMAN, L. G.; KANUK, L. L. Comportamento do consumidor. LTC, 2000.

SHEFRIN, H.; STATMAN, M. The Disposition to Sell Winners too Early and Ride Losers too Long: Theory and Evidence. Journal of Finance, v. 40, p. 777-791, 1985.

SILVA, C. A. T.; ARAÚJO, D. R. Aversão à perda nas decisões de risco. Revista de Educação e Pesquisa em Contabilidade, v. 2, n. 4, mar. 2007.

STRAHILEVITZ, M.; LOEWENSTEIN, G. The Effect of Ownership History on the Valuation of Objects. Journal of Consumer Research, v. 25, p. 276-89, dez. 1998.

THALER, R. Toward a positive theory of consumer choice. Journal of Economic Behavior and Organization, v. 1, p. 39-60, 1980.

TVERSKY, A.; KAHNEMAN, D. Advances in Prospect Theory: Cumulative Representation of Uncertainty. Journal of Risk and Uncertainty, v. 5, p. 297-323, 1992. 
WANG, M.; HUANG, H.; HSU, S. The Effect of Information Feedback Frequency and Investment Flexibility on Myopic Loss Aversion. Asian Economic and Financial Review, v. 3, n. 9, p. 1232-1248, 2013.

WEST, S. G.; FINCH, J. F.; CURRAN, P. J. Structural equation models with nonnormal variables: Problems and remedies. 1995.

WILLEMSEN, M. C.; BÖCKENHOLT, U. Choice by value encoding and value construction: processes of loss aversion. Journal of Experimental Psychology v. 140, n. 3, p. 303-324, 2011.

WOLF, J. R.; ARKES, H. R.; MUHANNA, Waleed A. The power of touch: An examination of the effect of duration of physical contact on the valuation of objects. Judgment and Decision Making, v. 3, n. 6, p. 476-482, 2008. 